\title{
Snow thickness retrieval over thick Arctic sea ice using SMOS satellite data
}

\author{
N. Maaß ${ }^{1}$, L. Kaleschke ${ }^{1}$, X. Tian-Kunze ${ }^{1}$, and M. Drusch ${ }^{2}$ \\ ${ }^{1}$ Institute of Oceanography, University of Hamburg, Bundesstraße 53, 20146 Hamburg, Germany \\ ${ }^{2}$ European Space Agency, ESA-ESTEC, 2200 AG Noordwijk, the Netherlands
}

Correspondence to: N. Maaß (nina.maass@zmaw.de)

Received: 30 June 2013 - Published in The Cryosphere Discuss.: 23 July 2013

Revised: 14 November 2013 - Accepted: 26 November 2013 - Published: 20 December 2013

\begin{abstract}
The microwave interferometric radiometer of the European Space Agency's Soil Moisture and Ocean Salinity (SMOS) mission measures at a frequency of $1.4 \mathrm{GHz}$ in the L-band. In contrast to other microwave satellites, low frequency measurements in L-band have a large penetration depth in sea ice and thus contain information on the ice thickness. Previous ice thickness retrievals have neglected a snow layer on top of the ice. Here, we implement a snow layer in our emission model and investigate how snow influences Lband brightness temperatures and whether it is possible to retrieve snow thickness over thick Arctic sea ice from SMOS data.

We find that the brightness temperatures above snowcovered sea ice are higher than above bare sea ice and that horizontal polarisation is more affected by the snow layer than vertical polarisation. In accordance with our theoretical investigations, the root mean square deviation between simulated and observed horizontally polarised brightness temperatures decreases from $20.9 \mathrm{~K}$ to $4.7 \mathrm{~K}$, when we include the snow layer in the simulations. Although dry snow is almost transparent in L-band, we find brightness temperatures to increase with increasing snow thickness under cold Arctic conditions. The brightness temperatures' dependence on snow thickness can be explained by the thermal insulation of snow and its dependence on the snow layer thickness. This temperature effect allows us to retrieve snow thickness over thick sea ice. For the best simulation scenario and snow thicknesses up to $35 \mathrm{~cm}$, the average snow thickness retrieved from horizontally polarised SMOS brightness temperatures agrees within $0.1 \mathrm{~cm}$ with the average snow thickness measured during the IceBridge flight campaign in the Arctic in
\end{abstract}

spring 2012. The corresponding root mean square deviation is $5.5 \mathrm{~cm}$, and the coefficient of determination is $r^{2}=0.58$.

\section{Introduction}

The Soil Moisture and Ocean Salinity (SMOS) mission carries the first satellite-based passive microwave radiometer that measures radiation emitted from the earth at a frequency of $1.4 \mathrm{GHz}$ in the L-band. The mission was successfully launched in 2009, and since spring 2010 observations have been made available to scientific and operational users (Mecklenburg et al., 2012). Although designed to provide global estimates of soil moisture and ocean salinity, L-band brightness temperatures measured by SMOS can be used to retrieve thin sea ice thickness (Kaleschke et al., 2010, 2012). In the previous retrieval methods, the sea ice was assumed to be snow free. Here, we investigate how a snow layer on top of the ice influences the brightness temperature above sea ice, and whether there is a relationship between the brightness temperature and the thickness of the snow layer.

Due to its high albedo, snow on sea ice is important for the surface energy balance. Additionally, snow affects the surface radiative properties of sea ice and thus modifies the remote sensing signal. Furthermore, information on snow thickness is required for the freeboard-based estimation of sea ice thickness from lidar and radar altimetry (Kwok and Cunningham, 2008; Giles et al., 2007). However, snow thickness observations over sea ice are scarce. The most comprehensive analysis for the Arctic Ocean is based on snow thickness and density measurements from the former Soviet Union drifting stations between 1954 and 1991 
(Warren et al., 1999). Though, it is not clear how well this climatology represents present-day snow conditions (Kurtz and Farrell, 2011). First cross-basin surveys of snow thickness over Arctic sea ice have been provided by airborne radar measurements (Kwok et al., 2011). However, airborne remote sensing is spatially and temporally restricted to individual campaigns. There is a snow thickness retrieval method for passive microwave satellite measurements that uses the spectral gradient ratio of the 19 and $37 \mathrm{GHz}$ vertical polarisation channels (e.g. Markus and Cavalieri, 1998). However, surface roughness variations introduce uncertainties to this method (Stroeve et al., 2006), and the method is only applicable to dry snow conditions and only to Antarctic sea ice and first-year ice in the Arctic, but fails over multi-year ice (Comiso et al., 2003). Thus, a method to estimate snow thickness over thick Arctic multi-year ice from SMOS brightness temperatures would improve monitoring of sea ice conditions in the Arctic from space.

The maximum ice thickness that can be retrieved from L-band radiometry depends on the dielectric properties of sea ice, which can be described by ice temperature and salinity (Kaleschke et al., 2010). The maximum retrievable ice thickness determines what we consider here as thin ice. For example, for sea ice with a salinity of $S_{\text {ice }}=8 \mathrm{~g} \mathrm{~kg}^{-1}$ and a bulk temperature of $T_{\text {ice }}=-5^{\circ} \mathrm{C}$, the maximum retrievable ice thickness in L-band is about $50 \mathrm{~cm}$ and increases to higher values for colder and less saline conditions (Kaleschke et al., 2010). The one ice layer radiation model used for sea ice thickness retrieval from SMOS in previous studies (Kaleschke et al., 2010, 2012) neglects the potential presence of a snow cover on sea ice. Snow is almost transparent for microwave radiation at $1.4 \mathrm{GHz}$ frequency (e.g. Hallikainen, 1989; Rott and Mätzler, 1987; Hall, 1996). However, the reflectivities at the ice-snow and the snow-air boundaries differ from the reflectivity at the ice-air boundary. Thus, a snow layer on the ice has an impact on the effective emissivity and accordingly on the brightness temperature of sea ice. Additionally, snow has a thermal insulation effect on ice, causing the bulk ice temperature of snow-covered sea ice generally to be higher than the bulk ice temperature of bare sea ice. Because the ice temperature determines the dielectric properties of sea ice, snow thus also has an indirect effect on the brightness temperature of sea ice.

Here, we use a multiple-layer model based on the radiation model presented in Burke et al. (1979) to examine the impact of a snow cover on brightness temperatures above sea ice and the implications for the ice thickness retrieval of snow-covered sea ice. In order to test the validity of our theoretical investigations, we simulate brightness temperatures for ice and snow thicknesses measured during the National Aeronautics and Space Administration (NASA) Operation IceBridge flight campaign in spring 2012 in the Arctic. We perform simulations that neglect and that include the snow layer, and compare these simulated brightness temperatures with brightness temperatures measured by SMOS. Further- more, we investigate whether there is a dependence between the brightness temperatures observed above snow-covered ice and the thickness of the snow cover on the ice. Finally, we evaluate whether SMOS has not only the potential for retrieving ice thickness over thin ice, but also the potential for estimating snow thickness over thick sea ice in the Arctic.

\section{Data and methods}

The analysis presented is based on three components: (1) an improved ice emission model to perform sensitivity studies and to simulate brightness temperatures for observed ice conditions, (2) SMOS brightness temperature measurements, and (3) measurements from the IceBridge campaign that provide model input and validation data. These three components are described in the following.

\subsection{Emission model}

In our model, the observed brightness temperature $T b$ over an ocean footprint with ice concentration $c_{\text {ice }}$ is

$$
\begin{aligned}
T b= & c_{\text {ice }}\left(T b_{\text {ice }}+R_{\text {ice }} T b_{\text {cosm }}\right) \\
& +\left(1-c_{\text {ice }}\right)\left(T b_{\text {water }}+R_{\text {water }} T b_{\text {cosm }}\right),
\end{aligned}
$$

where $T b_{\text {ice }}$ and $T b_{\text {water }}$ are the brightness temperatures of sea ice and open water, and $R_{\text {ice }}$ and $R_{\text {water }}$ are the reflectivities of sea ice and water, respectively. $T b_{\text {cosm }}$ is the uniform cosmic microwave background radiation, and has a value of $2.7 \mathrm{~K}$. The reflectivities $R$ are calculated from the emissivities $e$ via $R=1-e$. The brightness temperature of water is the water temperature times the emissivity of water, which we calculate using the Fresnel equations for a specular surface. The brightness temperature of sea ice has been determined with an emission model in previous studies (Kaleschke et al., 2010, 2012). Their model was based on the approach described in Menashi et al. (1993), which is valid for a dielectric slab of ice that is bordered by the underlying water and the air above the slab of ice. However, here we need a radiation model that describes radiation in an ice layer that is covered by a snow layer. Thus, we choose the radiation model described in Burke et al. (1979). This model is based on the radiative transfer equation and was originally developed for soil moisture applications of X- and L-band radiometer measurements. The model describes the radiation emitted from a stratified bare soil with $N$ layers. The dielectric properties are assumed to be constant across the layers. The radiation is assumed to be incoherent, that is, the layers' thickness variations within the illuminated footprint are considered to be large enough to destroy interference effects (Menashi et al., 1993). The surfaces of the layers are assumed to be smooth. For our sea ice applications, we consider a semi-infinite layer of air on top, a layer of snow on top of a layer of ice, and a semi-infinite layer of sea water 
at the bottom. The emission model then describes the brightness temperature above snow-covered sea ice as a function of the air permittivity, of the water temperature and permittivity, and of the temperatures, permittivities and thicknesses of the snow and the ice layer.

The permittivity of air is assumed to be $\epsilon_{\text {air }}=1$, which is the value for vacuum. For the permittivity of sea water, we here use the empirical relationship by Klein and Swift (1977) for a water salinity of $S_{\text {water }}=33 \mathrm{~g} \mathrm{~kg}^{-1}$. For the permittivity of sea ice, we use an empirical relationship that describes the ice permittivity $\left(\epsilon_{\text {ice }}\right)$ as a function of brine volume fraction $\left(V_{\mathrm{b}}\right)$ within the ice (Vant et al., 1978):

$\epsilon_{\text {ice }}=a_{1}+a_{2} V_{\mathrm{b}}+i\left(a_{3}+a_{4} V_{\mathrm{b}}\right)$,

where $V_{\mathrm{b}}$ is given in $\%$, and $a_{1}, a_{2}, a_{3}$, and $a_{4}$ are frequencydependent coefficients. Here, we use the coefficients for a frequency of $1.4 \mathrm{GHz}$ for multi-year ice as given in Kaleschke et al. (2010). The empirical relationship is valid for $V_{\mathrm{b}}<70 \%$. The brine volume fraction $V_{\mathrm{b}}$ can be expressed as a function of the bulk values for the ice salinity $\left(S_{\text {ice }}\right)$, the ice density $\left(\rho_{\text {ice }}\right)$, the density of the brine $\left(\rho_{\text {brine }}\right)$, and the ice temperature ( $\left.T_{\text {ice }}\right)$ (Cox and Weeks, 1983). For the ice density $\rho_{\text {ice }}$, we use an expression that relates $\rho_{\text {ice }}$ to ice temperature $\left(T_{\text {ice }}\right)$ (Pounder, 1965):

$\rho_{\text {ice }}=0.917-1.403 \times 10^{-4} T_{\text {ice }}$,

where $T_{\text {ice }}$ is given in ${ }^{\circ} \mathrm{C}$. For the brine density $\rho_{\text {brine }}$, we use an expression that depends on brine salinity $S_{\text {brine }}$ (Cox and Weeks, 1983):

$\rho_{\text {brine }}=1+0.0008 S_{\text {brine }}$,

where $S_{\text {brine }}$ is inserted in \%o. We obtain the brine salinity $S_{\text {brine }}$ from polynomial approximations for the dependency between brine salinity and ice temperature (Vant et al., 1978). For the snow permittivity, we use a polynomial fit obtained for snow permittivity measurements at microwave frequencies ranging between $840 \mathrm{MHz}$ and $12.6 \mathrm{GHz}$ (Tiuri et al., 1984). Based on these measurements, it is suggested that the permittivity of snow mainly depends on snow density and snow wetness and that the permittivity is practically independent of the structure of snow.

The water temperature is assumed to be at the freezing point of Arctic sea water $\left(T_{\mathrm{w}}=-1.8^{\circ} \mathrm{C}\right)$. In order to determine the bulk temperatures of the snow layer and the snowcovered ice layer, here we assume a balance of heat fluxes at the snow-ice interface and account for the different thermal conductivities of ice and snow. We assume that the temperature at the bottom of the ice is at the freezing point of water (i.e. $T_{\text {bottom }}=T_{\mathrm{w}}=-1.8^{\circ} \mathrm{C}$ ), and that the temperature gradients within ice and snow are linear. We assume that at the snow-ice interface the ice temperature equals the snow temperature: $T_{\text {ice }}\left(z=d_{\text {ice }}\right)=T_{\text {snow }}\left(z=d_{\text {ice }}\right)=T_{\text {si }}$ with $T_{\text {si }}$ being the snow-ice interface temperature, and $d_{\text {ice }}$ being the ice thickness. Here, $z$ denotes the vertical distance from the ice-water interface. Thus, $z$ is $z=0$ at the ice-water interface, $z=d_{\text {ice }}$ at the snow-ice interface, and $z=d_{\text {ice }}+d_{\text {snow }}$ at the snow surface. We assume that thermal conduction is continuous through the snow-ice interface (Maykut and Untersteiner, 1971):

$k_{\text {ice }} \gamma_{\text {ice }}\left(z=d_{\text {ice }}\right)=k_{\text {snow }} \gamma_{\text {snow }}\left(z=d_{\text {ice }}\right)$,

where

$\gamma_{\text {ice }}\left(z^{*}\right)=\left.\frac{\partial T_{\text {ice }}(z)}{\partial z}\right|_{z=z^{*}}$
$\gamma_{\text {snow }}\left(z^{*}\right)=\left.\frac{\partial T_{\text {snow }}(z)}{\partial z}\right|_{z=z^{*}}$,

and $k_{\text {ice }}$ and $k_{\text {snow }}$ are the thermal conductivities of ice and snow, respectively. Because we assume linear temperature gradients within the ice and the snow layer, $\gamma_{\text {ice }}(z)=\gamma_{\text {ice }}$ and $\gamma_{\text {snow }}(z)=\gamma_{\text {snow }}$ are constant values. The surface temperature $T_{\text {surf }}$ and the snow-ice interface temperature $T_{\mathrm{si}}$ are then described by

$T_{\text {surf }}=T_{\text {si }}+\gamma_{\text {snow }} d_{\text {snow }}$

$T_{\mathrm{si}}=T_{\mathrm{w}}+\gamma_{\text {ice }} d_{\text {ice }}$.

If we know the surface temperature $\left(T_{\text {surf }}\right)$, we can solve this system of three Eqs. (4), (7), and (8) and three unknowns $\gamma_{\text {ice, }}$ $\gamma_{\text {snow }}$, and $T_{\mathrm{si}}$. For the thermal conductivity of snow we use a constant climatological value of $k_{\text {snow }}=0.31 \mathrm{~W} \mathrm{~m}^{-1} \mathrm{~K}^{-1}$ (Yu and Rothrock, 1996), and for the thermal conductivity of ice we use a parameterisation accounting for ice temperature and salinity (Untersteiner, 1964):

$k_{\text {ice }}=2.034 \mathrm{~W} \mathrm{~K}^{-1} \mathrm{~m}^{-1}+0.13 \mathrm{~W} \mathrm{~kg}^{-1} \mathrm{~m}^{-2} \frac{S_{\text {ice }}}{T_{\text {ice }}-273}$.

To simplify the calculations we use the mean temperature of the snow and ice column $T_{\text {mean }}=0.5\left(T_{\text {surf }}+T_{\mathrm{w}}\right)$ instead of the ice temperature $T_{\text {ice }}$ in Eq. (9).

The bulk ice and snow temperatures $T_{\text {ice }}$ and $T_{\text {snow }}$ are then

$$
\begin{aligned}
T_{\text {ice }} & =\frac{1}{2}\left(T_{\mathrm{w}}+T_{\text {si }}\right) \\
& =T_{\mathrm{w}}+\frac{1}{2} K\left(T_{\text {surf }}-T_{\mathrm{w}}\right) k_{\text {snow }} d_{\text {ice }} \\
T_{\text {snow }} & =\frac{1}{2}\left(T_{\mathrm{si}}+T_{\text {surf }}\right) \\
& =\frac{1}{2}\left(T_{\mathrm{w}}+T_{\text {surf }}+K\left(T_{\text {surf }}-T_{\mathrm{w}}\right) k_{\text {snow }} d_{\text {ice }}\right)
\end{aligned}
$$

where $K=\left(k_{\text {ice }} d_{\text {snow }}+k_{\text {snow }} d_{\text {ice }}\right)^{-1}$.

In summary, the input parameters for the model are water temperature $\left(T_{\mathrm{w}}=-1.8^{\circ} \mathrm{C}=\right.$ constant $)$, water salinity $\left(S_{\text {water }}=33 \mathrm{~g} \mathrm{~kg}^{-1}=\right.$ constant $)$, surface temperature, bulk ice salinity, snow density and wetness, and ice and snow 
thickness. The expected ranges of values for these input parameters are as following: over thin sea ice, L-band brightness temperatures are mainly controlled by the ice thickness. As we here want to investigate the role of snow thickness, we focus on thicker sea ice of more than $1 \mathrm{~m}$ thickness. Depending on the season, 75 to $90 \%$ of the ice thicknesses in the Arctic are above this value of $1 \mathrm{~m}$ (Bourke and Garrett, 1987), although this fraction may have decreased due to a thinning of the ice cover (e.g. Rothrock et al., 1999). The bulk ice salinity of sea ice with a thickness of $1 \mathrm{~m}$ has been estimated to be about $6.3 \mathrm{~g} \mathrm{~kg}^{-1}$ and to decrease to $1.5 \mathrm{~g} \mathrm{~kg}^{-1}$ for ice thicknesses of $4 \mathrm{~m}$ (Cox and Weeks, 1974). The average snow density in the Arctic has been measured to vary between $250 \mathrm{~kg} \mathrm{~m}^{-3}$ in September and $320 \mathrm{~kg} \mathrm{~m}^{-3}$ in May (Warren et al., 1999). The simulation model works best for cold ice temperatures, and we expect large uncertainties during the melting season. Thus, we focus on ice surface temperatures below the freezing point and accordingly to a dry snow cover (snow wetness $W=0 \%$ ).

The input parameters used in our model are average bulk values. Because ice temperature and salinity, as well as snow density are usually not constant throughout the ice and snow pack of sea ice (e.g. Cox and Weeks (1974), Eicken (1992), Massom et al., 1997), using bulk values is a simplification that introduces uncertainties (Tonboe, 2013). However, with our current model we cannot estimate the impact of vertical variations in the ice, because the model neglects higher order reflection terms. Thus, introducing multiple layers within one medium (i.e. layers with only slightly differing permittivities) leads to brightness temperature changes that are higher than the changes caused by the vertical variations in the ice conditions. As a first approximation, the sensitivity of the brightness temperature to the changing bulk values of snow density, ice temperature, and salinity (Sect. 3.2) may be used to get an idea of the total impact of these quantities, although the influence of their vertical distribution cannot be studied explicitly with the current model.

\subsection{SMOS data}

SMOS is an Earth Explorer mission of the European Space Agency (ESA). The SMOS satellite was launched in November 2009 and achieves a global coverage every three days. The SMOS payload is a passive microwave 2-D interferometer: the Microwave Imaging Radiometer using Aperture Synthesis (MIRAS). MIRAS measures the microwave radiation emitted from the earth's surface at a frequency of $1.4 \mathrm{GHz}$ in the L-band (Kerr et al., 2001). The corresponding wavelength is $21 \mathrm{~cm}$. Every $1.2 \mathrm{~s}$ a two-dimensional snapshot is obtained, which contains observations under various viewing angles between 0 and $65^{\circ}$. The field of view is a hexagonlike shaped area about $1000 \mathrm{~km}$ across (Kerr et al., 2001). The resolution at the centre of the field of view (i.e. at nadir view) is about $35 \mathrm{~km}$ and decreases to about $50 \mathrm{~km}$ at the edge of the field of view (i.e. at incidence angles of $65^{\circ}$ ). MI-
RAS measures brightness temperatures at full polarisation. Thus, all parameters of the Stokes vector are provided. The radiometric accuracy of single measurements is 2.1 to $2.4 \mathrm{~K}$ (M. Martin-Neira, personal communication, 2013). For the retrieval in Sect. 5 we use brightness temperatures averaged over a range of incidence angles and over three days, including on average more than 280 measurements per grid point. Thus, we reduce the mean uncertainty by a factor of $\frac{1}{\sqrt{280}}$ to 0.12 to $0.14 \mathrm{~K}$.

In this study, we use SMOS Level 1C Version 505 data. The Level 1C product contains multi-angular brightness temperatures at the top of the atmosphere. The Level 1C data are geolocated in an equal-area Discrete Global Grid (DGG) system called ISEA 4H9 (Pinori et al., 2008). This grid is characterised by a uniform distance of $15 \mathrm{~km}$ between the cells. For every SMOS grid point, we first gather all Level 1C brightness temperatures and the auxiliary data provided during one day. The latitude, the longitude, and the grid point number of each measurement are stored together with the brightness temperatures at full polarisation, the incidence angles, the Faraday rotation angles, and the georotation angles. The Level $1 \mathrm{C}$ brightness temperatures are given in the antenna reference frame, and thus have to be transformed to the earth reference frame if the horizontal and the vertical polarisation are considered. This correction for the geometrical rotation is combined with the correction for Faraday rotation (Zine et al., 2008). The MIRAS radiometer alternately measures one or two of the four Stokes vector components per snapshot. For the data processing of SMOS brightness temperatures in this study, we thus use the four Stokes vector components, as well as the Faraday rotation and the georotation angles from subsequent snapshots to calculate the horizontally and vertically polarised brightness temperatures for the considered SMOS grid point.

SMOS measurements are affected by radio-frequency interference (RFI) that originates from radars, TV stations, and radio transmission (Oliva et al., 2012). Until now, it is not clear how to deal most effectively with the problems caused by RFI contamination. There are several algorithms under development (e.g. Camps et al., 2010; Oliva et al., 2012; Misra and Ruf, 2012). In this study, we use the following approach. We collect all horizontally and vertically polarised SMOS brightness temperatures measured within a SMOS grid point. These brightness temperatures are sorted according to their incidence angles. In a first step, we exclude all brightness temperatures that are not in the range of 50-280 K, because we do not expect natural radiation to take values outside of this range for sea ice applications. If, after this step, we have more than ten brightness temperatures for each polarisation and cover at least an incidence angle range of $10^{\circ}$ per grid point, we use the remaining brightness temperatures to calculate a third order polynomial fit of the SMOS brightness temperatures as a function of incidence angle. The polynomial fit is calculated separately for the horizontal and the 
vertical polarisation. All brightness temperatures that deviate more than $15 \mathrm{~K}$ from this polynomial fit are excluded from the further analysis. Due to the transformation from the antenna reference frame to the earth reference frame, the brightness temperatures at horizontal and at vertical polarisation are interdependent and in both exclusion steps both polarisations are excluded, even if only one of them does not fulfill the conditions.

The value of $15 \mathrm{~K}$ for the exclusion of brightness temperatures is determined after visual inspection of example cases and is only a rough estimation. Furthermore, fitting the brightness temperatures at horizontal and vertical polarisation as a function of incidence angle by two separate third order polynomials can be problematic, especially for low incidence angles, where horizontally and vertically polarised brightness temperatures should be nearly equal. However, we do not expect our RFI filter processing to introduce significant errors.

\subsection{The IceBridge flight campaign}

For simulation of brightness temperatures, we use ice and snow thicknesses measured during the NASA Operation IceBridge mission (Kurtz et al., 2012). We use the data from the flight campaign that took place from 14 March to 2 April 2012 in the Arctic. The NASA IceBridge Sea Ice Freeboard, Snow Depth, and Thickness (IDCSI2) data set contains derived geophysical data products including sea ice thickness retrieved from the Airborne Topographic Mapper (ATM) laser altimeter, and snow depth retrieved from the IceBridge snow radar. Simultaneously, the ice surface temperature was measured by a KT19.85 infrared pyrometer alongside the ATM instrument. The IceBridge flight tracks and the measured snow thicknesses are depicted in Fig. 10.

The ice thickness measurements with the ATM laser altimeter have a circular footprint of about $1 \mathrm{~m}$ in size (Kurtz et al., 2013). In spring 2009, airborne ATM laser altimeter measurements and temporally and spatially coincident in situ sea ice thickness measurements were conducted on sea ice north of Greenland (GreenArc campaign). The mean sea ice thickness retrieved from laser altimeter data and the mean in situ sea ice thickness agreed within $5 \mathrm{~cm}$, while the modal values agreed within $10 \mathrm{~cm}$ (Farrell et al., 2012). From this analysis, the uncertainty of the IceBridge sea ice thicknesses was estimated to be about $40 \mathrm{~cm}$. However, in general, the uncertainty of the ice thickness measurements is variable and depends on the number and distance to sea surface reference points (Kurtz et al., 2013). The average ice thickness of all IceBridge ice thickness measurements obtained between 14 March and 2 April 2012 is about $4 \mathrm{~m}$, and the flight tracks were mainly located over multi-year ice. Only a very small fraction of the measurements was carried out over ice below $1 \mathrm{~m}$ in ice thickness. Thus, the IceBridge measurements are not suitable for a validation of the ice thickness retrieval from SMOS brightness temperatures. However, here we use the IceBridge measurements to examine whether we can use our radiation model to realistically simulate L-band brightness temperatures over snow-covered thick sea ice.

The footprint size of the IceBridge snow radar is about $15 \mathrm{~m} \times 16 \mathrm{~m}$ (Farrell et al., 2012). The GreenArc campaign served also as a validation for the IceBridge snow thicknesses. The mean snow thickness retrieved from radar data and the mean in situ snow thickness agreed within $1 \mathrm{~cm}$, while the modal values agreed within $2 \mathrm{~cm}$ (Farrell et al., 2012). The correlation coefficient between the snow thicknesses was $r=0.7$, i.e. $r^{2}=0.49$ (Farrell et al., 2012). The agreement between airborne and in situ measurements was very good over level ice, while the observed differences were larger over multi-year ice, particularly at pressure ridges. A comparison of the mean radar derived snow thicknesses with climatological snow thicknesses (Warren et al., 1999) revealed a difference of $0.3 \mathrm{~cm}$ over multi-year ice and of $16.5 \mathrm{~cm}$ over first-year ice (Kurtz and Farrell, 2011). From comparison of the 2009 and 2010 flights with in situ measurements, the uncertainty of the IceBridge snow thickness has been estimated to be about $6 \mathrm{~cm}$ (Kurtz et al., 2013).

The footprint size of the KT19.85 infrared pyrometer is about $40 \mathrm{~m}$ (Kurtz, 2012). Here, we use the KT19.85 temperature data (Krabill, 2012) to estimate the surface temperature of (snow-covered) sea ice. The uncertainty of the surface temperature data is assumed to be around $0.5 \mathrm{~K}$ (Kurtz, 2012). Additionally, in case of clouds or fog underneath the aircraft, the instrument measures the cloud temperature instead of the ice surface temperature (Kurtz, 2012).

\section{Model simulations and sensitivities}

In this section, we first use our emission model to theoretically investigate the impact of a snow layer on brightness temperatures over thin sea ice and thus on the ice thickness retrieval from L-band measurements. For thin ice, the brightness temperature is mainly sensitive to the ice layer's thickness. Whether the brightness temperature of thick ice depends on the snow layer thickness is investigated in the second part of this section.

\subsection{Thermal insulation and dielectric properties of snow}

We use our radiation model to simulate brightness temperatures over snow-covered sea ice for typical Arctic winter conditions: snow density is set to $\rho_{s}=300 \mathrm{~kg} \mathrm{~m}^{-3}$, and the snow is assumed to be dry (wetness $W=0 \%$ ) and to have a thickness of $10 \%$ of the ice thickness (Doronin, 1971). The surface temperature is $T_{\text {surf }}=-20^{\circ} \mathrm{C}$. Simulations are performed for brightness temperatures at an incidence angle $\theta=45^{\circ}$ at horizontal and at vertical polarisation. In order to investigate the impact of the snow cover on the brightness temperatures due to the dielectric properties of snow 


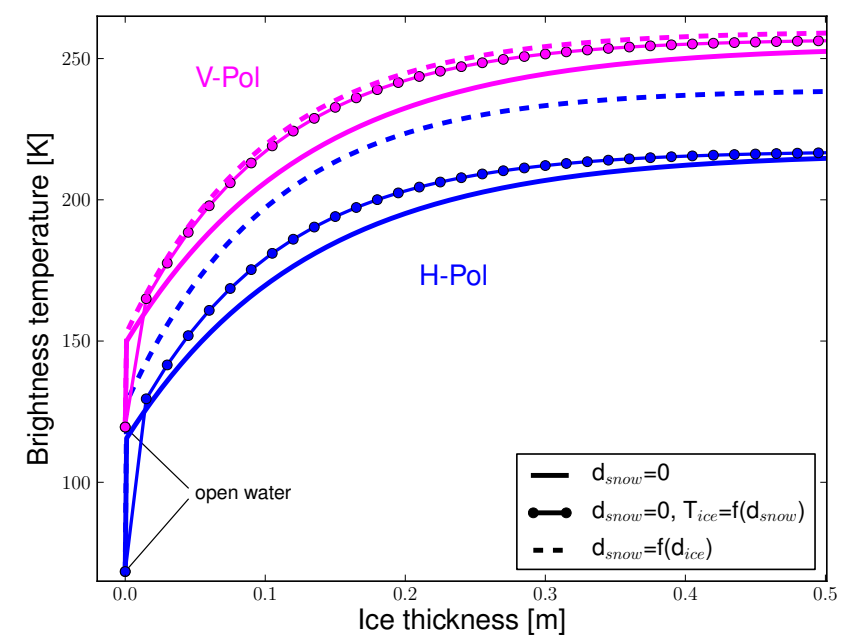

Fig. 1. Brightness temperature at horizontal (blue) and vertical (magenta) polarisation for an incidence angle $\theta=45^{\circ}$ as a function of ice thickness for three different scenarios: (1) the solid lines show brightness temperatures as modelled for snow-free sea ice; (2) the circles show brightness temperatures as modelled for snow-free sea ice with ice temperatures, as if the snow cover was present; and (3) the dashed lines show brightness temperatures as modelled for snow-covered sea ice.

separately from the impact due to the thermal insulation effect of snow, we compare three different scenarios for the brightness temperature as a function of ice thickness:

1. Bare sea ice without a snow cover.

2. Bare sea ice without a snow cover, but a bulk ice temperature as if the thermal insulation effect of snow was present. The bulk ice temperature is calculated from the snow thickness using Eq. (11).

3. Sea ice covered with snow, where the bulk snow and ice temperatures are as calculated from Eqs. (13) and (11), respectively.

The snow layer causes the modelled brightness temperatures to increase (Fig. 1). The brightness temperature increase is higher for horizontal than for vertical polarisation. For our example case, the snow layer causes brightness temperatures for $50 \mathrm{~cm}$ thick ice to increase by $23 \mathrm{~K}$ at horizontal and by $6 \mathrm{~K}$ at vertical polarisation $\left(\theta=45^{\circ}\right)$. At horizontal polarisation, the relative contribution of the increased ice temperature to the overall brightness temperature increase is relatively small. This contribution by thermal insulation is higher for small ice thicknesses and declines with increasing ice thickness. At vertical polarisation, the increased ice temperature under the snow cover is almost solely responsible for the brightness temperature increase.

We do not show the results for other incidence angles or surface temperatures here, but we state that at nadir view $\left(\theta=0^{\circ}\right)$ the impact of a snow layer on the brightness temperature is about the average of the increases at horizontal and at vertical polarisation shown here for $\theta=45^{\circ}$. When the incidence angle increases from $\theta=0^{\circ}$, the brightness temperature increase caused by snow increases for horizontal polarisation and decreases for vertical polarisation. For higher surface temperatures, the thermal insulation of snow causes brightness temperatures to increase less, because the brightness temperatures are less sensitive to ice temperature at higher temperatures. For surface temperatures higher than about $-10^{\circ} \mathrm{C}$, the thermal insulation even causes a decrease of brightness temperature (for the conditions considered here). At vertical polarisation, the brightness temperatures of warmer sea ice are thus very similar for snowcovered and snow-free sea ice. While at horizontal polarisation the overall effect of a snow layer is still an increase of the brightness temperature of snow-covered ice compared to snow-free ice, because the contribution of the dielectric properties is higher than the contribution by thermal insulation of snow.

Because the emission model by Burke et al. (1979) is based on the radiative transfer equation, the model does not converge to the correct solution for layer thicknesses approaching zero (Menashi et al., 1993). Thus, we see a jump in the brightness temperature from open water to a very thin ice layer, as well as from bare sea ice to sea ice that is covered by a very thin snow layer (Fig. 1). Moreover, in further studies we found that the emission model after Burke et al. (1979) is not suitable for considering multiple layers within ice, because the model neglects higher order reflection terms (Maßß, 2013). Therefore, the emission model after Burke et al. (1979) has been compared to a coherent model, described in Ulaby et al. (1981), that is based on the Maxwell equations and accounts for higher order reflection terms (Maaß, 2013). Except for the first few centimetres of ice and snow layer thickness the brightness temperatures from these two models agreed well. Thus, we think that although the emission model after Burke et al. (1979) neglects higher order reflection terms and does not describe the transition from a non-existing layer to a very thin layer (a few centimetres), our emission model is able to capture the brightness temperature changes caused by a layer of snow on top of sea ice.

\subsection{Snow thickness}

After investigating the impact of a snow layer with a typical thickness on top of relatively thin ice in the previous part, we now investigate whether the brightness temperature over thick ice depends on the thickness of the snow layer. Therefore, we use our model to calculate the brightness temperature over $4 \mathrm{~m}$ thick multi-year ice as a function of snow thickness. In one simulation we account for the thermal insulation effect of snow, in the other simulation we consider only the dielectric properties of snow. As in the previous investigation, snow density is $\rho_{d}=300 \mathrm{~kg} \mathrm{~m}^{-3}$, and the snow is assumed to be dry. The simulations are performed for two 


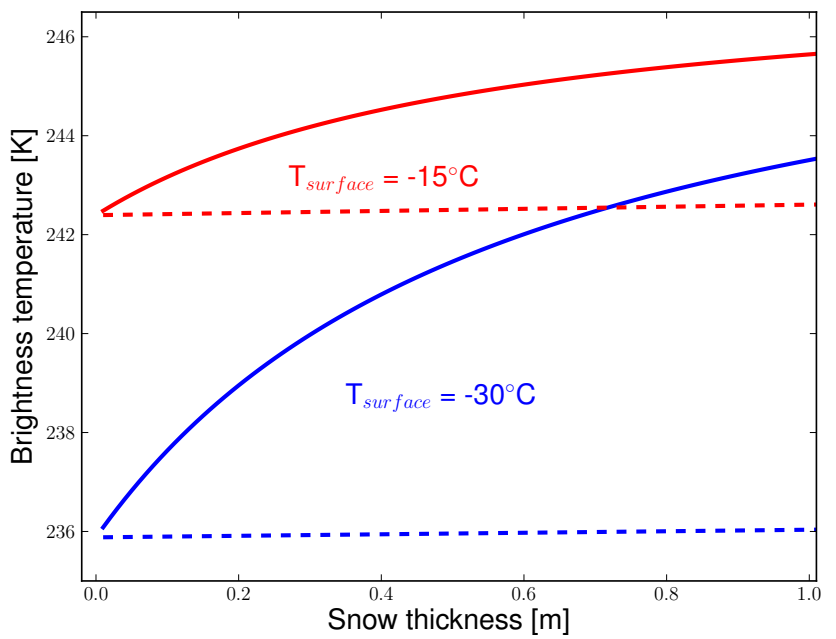

Fig. 2. Brightness temperature of $4 \mathrm{~m}$ thick snow-covered ice as a function of snow thickness at horizontal polarisation at an incidence angle $\theta=45^{\circ}$ (solid line) for an ice surface temperature of $-30^{\circ} \mathrm{C}$ (blue) and of $-15^{\circ} \mathrm{C}$ (red). The dashed line indicates the brightness temperature of snow-covered ice, when the thermal insulation by snow is neglected.

surface temperatures $\left(T_{\text {surf }}=-15^{\circ} \mathrm{C}\right.$ and $\left.T_{\text {surf }}=-30^{\circ} \mathrm{C}\right)$. Here, we consider horizontally polarised brightness temperatures at an incidence angle $\theta=45^{\circ}$.

We find that, if we consider only the dielectric properties of snow, the thickness of the snow layer does not influence brightness temperatures in the considered range of snow thicknesses (Fig. 2). However, if we take into account the thermal insulation by snow, the brightness temperature increases with increasing snow thickness. A thicker snow layer has a higher insulation effect and thus the bulk ice temperature under a thick snow layer is higher than under a thin snow layer. In our investigations the brightness temperature thus increases by $6.4 \mathrm{~K}$ when the snow thickness increases from 0 to $50 \mathrm{~cm}$ for $T_{\text {surf }}=-30^{\circ} \mathrm{C}$. For higher temperatures $\left(T_{\text {surf }}=-15^{\circ} \mathrm{C}\right)$, brightness temperature is less sensitive to snow thickness, and the brightness temperature increases by $2.4 \mathrm{~K}$, when the snow thickness increases to $50 \mathrm{~cm}$.

For thin ice, the sensitivities of brightness temperature to ice thickness and to snow thickness are similar (not shown here). Thus, we cannot distinguish between an increasing ice and an increasing snow thickness. For thick ice (as compared to the maximum retrievable ice thickness), the sensitivity of brightness temperature to snow thickness is about an order of magnitude higher than the sensitivity to ice thickness. For Arctic applications, the sensitivity to snow thickness is roughly ten times higher than the sensitivity to ice thickness for ice thicknesses of more than approximately $1.5 \mathrm{~m}$. Thus, we here focus on the influence of snow thickness on brightness temperatures over relatively thick sea ice.

Figure 3 shows the sensitivity of brightness temperature to surface temperature, ice thickness, ice salinity, and snow
Table 1. The ice parameters $r$ influencing the brightness temperature, their average values $\bar{r}$ (as used in Fig. 3 for all parameters except for the one that is varied), the ranges in which the parameters are varied $\Delta r$, and the impact on the brightness temperature $\Delta T B$.

\begin{tabular}{lrrr}
\hline$r$ & $\bar{r}$ & $\Delta r$ & $\Delta T B[\mathrm{~K}]$ \\
\hline$d_{\text {ice }}$ & $4 \mathrm{~m}$ & $2 \mathrm{~m}$ & 0.5 \\
$d_{\text {snow }}$ & $20 \mathrm{~cm}$ & $40 \mathrm{~cm}$ & 5.6 \\
$T_{\text {surf }}$ & $-33.15^{\circ} \mathrm{C}$ & $4 \mathrm{~K}$ & 1.4 \\
$S_{\text {ice }}$ & $1.5 \mathrm{~g} \mathrm{~kg}^{-1}$ & $2 \mathrm{~g} \mathrm{~kg}^{-1}$ & 0.9 \\
$\rho_{\text {snow }}$ & $300 \mathrm{~kg} \mathrm{~m}^{-3}$ & $80 \mathrm{~kg} \mathrm{~m}^{-3}$ & 0.7 \\
\hline
\end{tabular}

density, in comparison to the sensitivity to snow thickness for the ice conditions encountered during the IceBridge campaign (see Sect. 4). For this first estimation of sensitivity, we assume constant average values for all model parameters except for one, which is varied within a range of values. The corresponding average values, the ranges in which the parameters are varied, and the impact on the brightness temperature are given in Table 1 . We consider the given ranges to be representative for the uncertainties associated with the parameters when these are estimated from satellite observations or a climatology, for example. The uncertainties would be half of the ranges given here. For example, the uncertainty of the MODerate Resolution Imaging Spectroradiometer (MODIS) ice surface temperature product is given to be 1.2-1.3 K (Hall et al., 2004), here we use $2 \mathrm{~K}$. Uncertainty in snow density has been estimated to be $20 \mathrm{~kg} \mathrm{~m}^{-3}$ over multiyear ice and $50 \mathrm{~kg} \mathrm{~m}^{-3}$ over first-year ice (Alexandrov et al., 2011). As a first estimation we here use $40 \mathrm{~kg} \mathrm{~m}^{-3}$ for the snow density's uncertainty. We use an empirical relationship between ice thickness and ice salinity (Cox and Weeks, 1974) to account for the empirical covariance of these two parameters in our simulations. The remaining parameters are varied independently of each other, thus providing a simple mean to estimate and to compare the different model parameters' impact on brightness temperature. The impact of the snow thickness, which is what we want to retrieve, is the highest (Table 1). When we apply the Gaussian error propagation formula, the sensitivities of brightness temperature to ice thickness, surface temperature, ice salinity, and snow density and their estimated uncertainties result in an uncertainty in brightness temperature of $0.9 \mathrm{~K}$. For the snow thickness retrieval in the range of snow thicknesses $0-40 \mathrm{~cm}$ this leads to a snow thickness uncertainty of $6.7 \mathrm{~cm}$ for the given ice conditions.

In order to test the validity of our theoretical considerations, in the following section, we simulate brightness temperatures over snow-covered sea ice and compare these brightness temperature simulations with SMOS brightness temperature measurements. In the subsequent section, we investigate whether brightness temperatures as observed by 


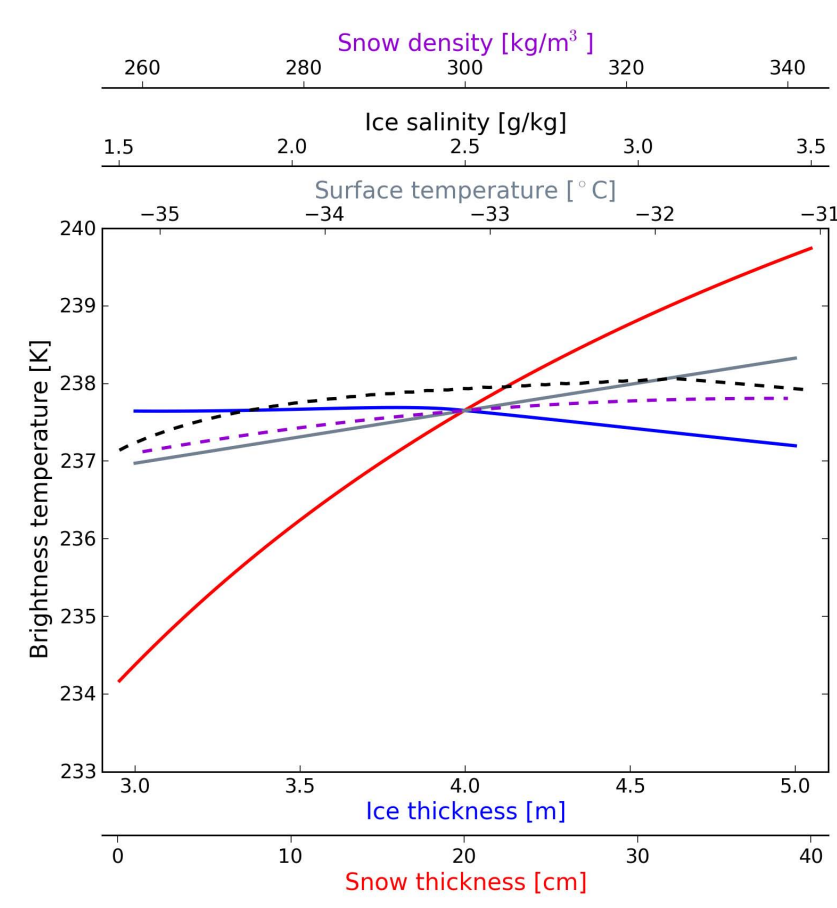

Fig. 3. Horizontally polarised brightness temperature (incidence angle $\theta=45^{\circ}$ ) as it varies with ice thickness, snow thickness, surface temperature, ice salinity, or snow density, respectively. The assumed values, the variation ranges, and the corresponding changes in brightness temperature are given in Table 1.

SMOS over thick Arctic sea ice depend on snow thickness and whether there is a potential for retrieving snow thickness from SMOS observations.

\section{Comparison of brightness temperature simulations and SMOS observations}

We compare two different brightness temperature simulations with brightness temperatures measured by SMOS. For one simulation our emission model is applied to one ice layer and the ice thickness information from IceBridge measurements. In this simulation we neglect a potential snow cover. For the other simulation our emission model is applied to one layer of ice that is covered by one layer of snow; the ice and snow layer thicknesses are taken from the IceBridge measurements.

We simulate brightness temperatures for every SMOS grid cell that contains at least 50 single IceBridge measurements. For the simulations, we use the mean values of all IceBridge ice and snow thickness measurements that are located within the SMOS grid cell as model input for ice and snow thickness. The bulk ice salinity for the SMOS grid cell is estimated from the mean ice thickness using an empirical relationship between ice salinity and ice thickness in the Arctic (Cox and Weeks, 1974). This empirical relationship was determined for ice thicknesses up to $4 \mathrm{~m}$. For thicker ice we use the value for $4 \mathrm{~m}$ ice thickness, which is $S_{\text {ice }}=1.5 \mathrm{~g} \mathrm{~kg}^{-1}$. Ice and snow temperatures are estimated from the KT19 ice surface temperatures measured during the IceBridge flight campaign. For the snow-free simulations, we use the mean value between the KT19 ice surface temperature and the water temperature as model input for the ice temperature. For the simulations that include a snow layer, we use equations (11) and (13) to calculate ice and snow temperatures for the model from KT19 ice surface temperatures. As model input for ice concentration, we use ice concentrations that have been retrieved from the $85 \mathrm{GHz}$ channel of SSMIS using the ARTIST Sea Ice (ASI) algorithm (Kaleschke et al., 2001; Spreen et al., 2008). The ice concentration data are given on a polar stereographic grid with $12.5 \mathrm{~km}$ grid resolution. The data are 5 day median filtered in order to mitigate unrealistic short-term sea ice concentration variations due to weather effects. For snow density we assume a value of $\rho_{\text {snow }}=320 \mathrm{~kg} \mathrm{~m}^{-3}$, which is a climatological average value for the Arctic in March (Warren et al., 1999), and was also used by Kurtz et al. (2013), for example. According to the IceBridge surface temperatures, the campaign was conducted under freezing conditions. Thus, we expect the ice to be covered by dry snow and assume a snow wetness of $W=0 \%$ in the model.

Because ice concentration and ice temperature have a large influence on the modelled brightness temperatures, we in a second comparison constrain the pixels with respect to (a) ice concentration and (b) ice temperature. (a) The difference between the brightness temperature of thick ice (for our purposes: $d_{\text {ice }}>0.5 \mathrm{~m}$ in the Arctic) and water is typically on the order of $130 \mathrm{~K}$. For example, an error of only $5 \%$ in the ice concentration would thus cause an error in the brightness temperature of about $6.5 \mathrm{~K}$. The uncertainty of ASI ice concentrations is higher for low ice concentrations than for high ice concentrations. The theoretically expected standard deviation of ice concentration is about $25 \%$ for ice concentrations around $c_{\text {ice }}=0 \%$, about $13 \%$ for $c_{\text {ice }}=50 \%$, and about $6 \%$ for $c_{\text {ice }}=100 \%$ (Spreen et al., 2008). A comparison with in situ data and high-resolution satellite data revealed a standard deviation of almost $5 \%$ for ice concentrations $c_{\text {ice }}>90 \%$ (Andersen et al., 2007). Thus, in a second comparison, we consider only cases with an almost closed ice cover and use only pixels with measured ice concentrations $c_{\text {ice }} \geq 95 \%$, and set the ice concentration in the model to $c_{\text {ice }}=100 \%$. (b) Because we do not know how reliable the KT19 surface temperature information is, we perform the simulations in the second comparison for a fixed surface temperature. Therefore, we calculate the average surface temperature from all KT19 measurements that are included in our analysis. As model input for the surface temperature, we then use this average value and include only pixels with surface temperatures that are within one standard deviation of the average surface temperature. The average surface temperature for all pixels with ice concentrations 
$c_{\text {ice }} \geq 95 \%$ is $\overline{T_{\text {surf }}}=-32.8^{\circ} \mathrm{C}$, and the standard deviation is $\sigma_{T_{\text {surf }}}=4.5^{\circ} \mathrm{C}$.

Thus, here we compare SMOS brightness temperatures with brightness temperature simulations that neglect and that include a snow layer:

1. for all ice concentrations and surface temperatures, ice concentration and surface temperature are variable; and

2. only for almost completely ice-covered cases $\left(c_{\text {ice }} \geq\right.$ $95 \%$ ) and only for surface temperatures within one standard deviation of the average surface temperature $\left(-37.3^{\circ} \mathrm{C}<T_{\text {surf }}<-28.3^{\circ} \mathrm{C}\right)$, the ice concentration is set to $c_{\text {ice }}=100 \%$ and the surface temperature is set to the average value $T_{\text {surf }}=-32.8^{\circ} \mathrm{C}$.

For the comparison with simulated brightness temperatures, we use all SMOS brightness temperatures with incidence angles $\theta$ between 0 and $60^{\circ}$. For each SMOS pixel we average the brightness temperatures measured at $\theta=0-10^{\circ}$, for the remaining incidence angles we average the brightness temperatures over $5^{\circ}$ incidence-angle intervals (i.e. for 10 $\left.15,12.5-17.5,15-20, \ldots, 55-60^{\circ}\right)$. The simulations are calculated for the corresponding mean incidence angles $\theta=5$, $12.5,15,17.5, \ldots, 57.5^{\circ}$.

\subsection{Results for all ice concentrations and all ice surface temperatures}

For this simulation scenario, the simulations that neglect and that include a snow layer differ considerably for horizontal polarisation, while, at vertical polarisation, the impact of a snow layer is smaller (Fig. 4). For both polarisations, the modelled brightness temperatures increase, when a snow layer is added. Contemporaneously, the range of brightness temperatures decreases, when a snow layer is added. At horizontal polarisation, brightness temperatures at low incidence angles $\left(\theta<15^{\circ}\right)$ increase by about $13 \mathrm{~K}$, while brightness temperatures at high incidence angles $\left(\theta>50^{\circ}\right)$ increase by about $26 \mathrm{~K}$, when a snow layer is added. The range of brightness temperatures for different incidence angles decreases from about $60 \mathrm{~K}$, when neglecting the snow cover, to about $47 \mathrm{~K}$, when including the snow cover. At vertical polarisation, brightness temperatures at low incidence angles $\left(\theta<15^{\circ}\right)$ increase by about $10 \mathrm{~K}$, while brightness temperatures at high incidence angles $\left(\theta>50^{\circ}\right)$ increase only by about $3 \mathrm{~K}$, when a snow layer is added. The range of values decreases from about $35 \mathrm{~K}$, when neglecting the snow cover, to about $28 \mathrm{~K}$, when including the snow cover.

At horizontal polarisation, including the snow layer considerably reduces the deviations between simulated and measured brightness temperatures (Table 2). When neglecting the snow layer, the simulations underestimate the measured brightness temperatures on average by $23.7 \mathrm{~K}$, as compared to an average underestimation by $3.6 \mathrm{~K}$, when the snow layer
Table 2. Root mean square deviations RMSD, mean deviations MD, and coefficients of determination $r^{2}$ for simulated brightness temperatures and brightness temperatures as measured by SMOS for horizontal and vertical polarisation.

\begin{tabular}{lllrr}
\hline & & & Scenario 1 & Scenario 2 \\
\hline \multirow{4}{*}{ H-Pol } & \multirow{2}{*}{ RMSD [K] $[\mathrm{K}]$} & no snow & 25.5 & 20.9 \\
& & snow & 7.4 & 4.7 \\
& & no snow & 23.7 & 19.3 \\
& \multirow{2}{*}{$r^{2}$} & snow & 3.6 & -1.6 \\
& & no snow & 0.44 & 0.58 \\
& & snow & 0.38 & 0.61 \\
\hline \multirow{4}{*}{ V-Pol } & \multirow{2}{*}{ RMSD [K] } & no snow & 8.8 & 5.3 \\
& & snow & 5.8 & 7.9 \\
& & no snow & 6.1 & 2.2 \\
& \multirow{2}{*}{$r^{2}$} & snow & -2.7 & -7.0 \\
& & no snow & 0.25 & 0.39 \\
Data points $N$ & snow & 0.18 & 0.41 \\
\hline
\end{tabular}

is included. The coefficients of determination are rather similar for the simulations without and with snow $\left(r^{2}=0.44\right.$ and $r^{2}=0.38$, respectively). Compared to the horizontal polarisation, at vertical polarisation the coefficients of determination between the simulated and the observed brightness temperatures are considerably smaller, as well as the differences between simulations that neglect and that include the snow layer (Table 2).

\subsection{Results for the closed ice cover cases and a fixed surface temperature}

Figure 5 shows the results for comparing only the pixels that are almost completely ice covered and that have a surface temperature within one standard deviation of the average surface temperature $\left(-37.3^{\circ} \mathrm{C}<T_{\text {surf }}<-28.3^{\circ} \mathrm{C}\right)$. Compared to scenario 1 , the root mean square deviations decrease, and the coefficients of determination increase. At horizontal polarisation, the root mean square deviation between simulated and measured brightness temperatures is $20.9 \mathrm{~K}$ when the snow layer is neglected, and decreases to $4.7 \mathrm{~K}$ when the snow layer is included. The coefficients of determination are $r^{2}=0.58$ without snow, and $r^{2}=0.61$ with snow.

\section{Potential for retrieval of snow thickness}

The above comparison between measured and modelled brightness temperatures suggests that brightness temperatures observed by SMOS are influenced by the presence of a snow layer on top of the ice. According to the results from the previous sections, brightness temperatures over snowcovered sea ice are independent of snow layer thickness, when only the dielectric properties of the snow layer are 

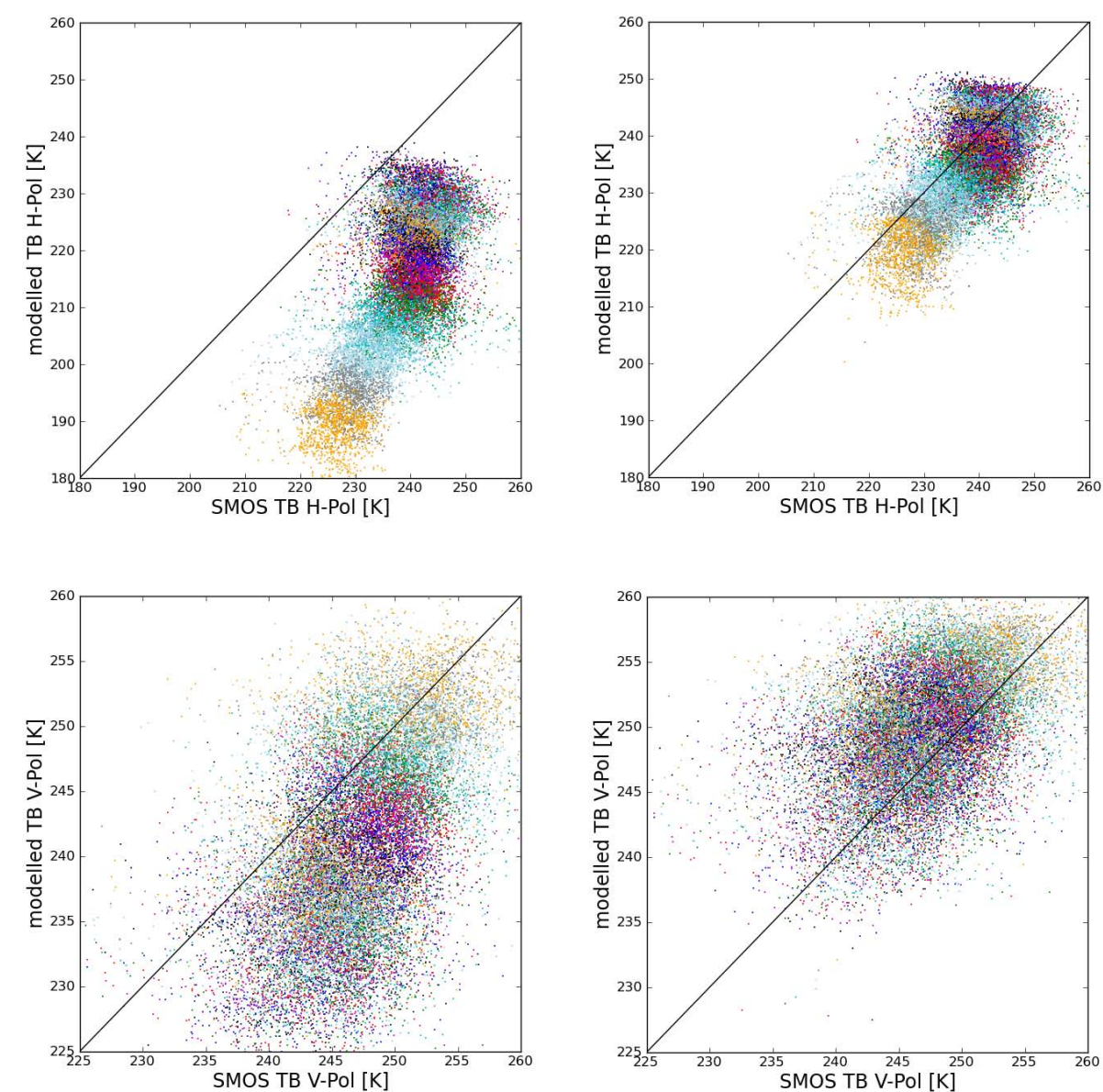

Fig. 4. Brightness temperatures as measured by SMOS vs. brightness temperatures as modelled with the model for one ice layer and the IceBridge ice thicknesses (left figures), and as modelled with the model for one ice and one snow layer and the IceBridge ice and snow thicknesses (right figures), respectively. The upper figures show horizontal polarisation, the lower figures vertical polarisation. The colors indicate the incidence angle increasing from 0 at the upper right corner to $60^{\circ}$ at the lower left corner of the data cloud at horizontal polarisation, and from 0 at the lower left corner to $60^{\circ}$ at the upper right corner at vertical polarisation.

considered. However, due to the thermal insulation effect of snow, there is an indirect effect of snow thickness on brightness temperatures. This indirect effect is the basis for a potential suitability of L-band brightness temperatures for a retrieval of snow thickness. According to our theoretical considerations, we expect this potential to be given only for relatively thick ice. Thus, in the following we exclude all IceBridge pixels with average ice thicknesses of less than $1 \mathrm{~m}$.

\subsection{Brightness temperatures for different snow thicknesses}

In order to investigate this indirect impact of snow layer thickness on observed brightness temperatures, we divide the IceBridge measurements into five snow thickness classes and consider the corresponding SMOS brightness temperatures. We choose the snow thickness classes such that each class is represented by approximately the same amount of observations. The snow thickness classes are (1) $d_{\text {snow }}=6-14 \mathrm{~cm}$,
(2) $d_{\text {snow }}=14-20 \mathrm{~cm}$, (3) $d_{\text {snow }}=20-26 \mathrm{~cm}$, (4) $d_{\text {snow }}=$ $26-30 \mathrm{~cm}$, and (5) $d_{\text {snow }}=30-40 \mathrm{~cm}$. Every snow thickness class contains between 116 and 148 SMOS grid cells. These grid cells contain at least 50 IceBridge snow thickness measurements and contemporaneous SMOS brightness temperatures. SMOS brightness temperatures are averaged over incidence angle ranges of $5^{\circ}$ (except for the incidence angles averaged over $\theta=0-10^{\circ}$ ), as was done in the previous section.

For comparison, we not only consider the observed brightness temperatures, but also simulate brightness temperatures for the snow thickness classes 1 to 5 . We use fixed values for the ice concentration, ice thickness, ice salinity, and ice surface temperature. We use only SMOS grid cells with measured $c_{\text {ice }} \geq 95 \%$ and set the ice concentration in the model to $c_{\text {ice }}=100 \%$. For ice thickness in the model, we use the average value of all IceBridge ice thickness measurements with $c_{\text {ice }} \geq 95 \%$, which is $\overline{d_{\text {ice }}}=4 \mathrm{~m}$. Accordingly, the ice salinity in the model is set to $S_{\text {ice }}=1.5 \mathrm{~g} \mathrm{~kg}^{-1}$ (Cox and 

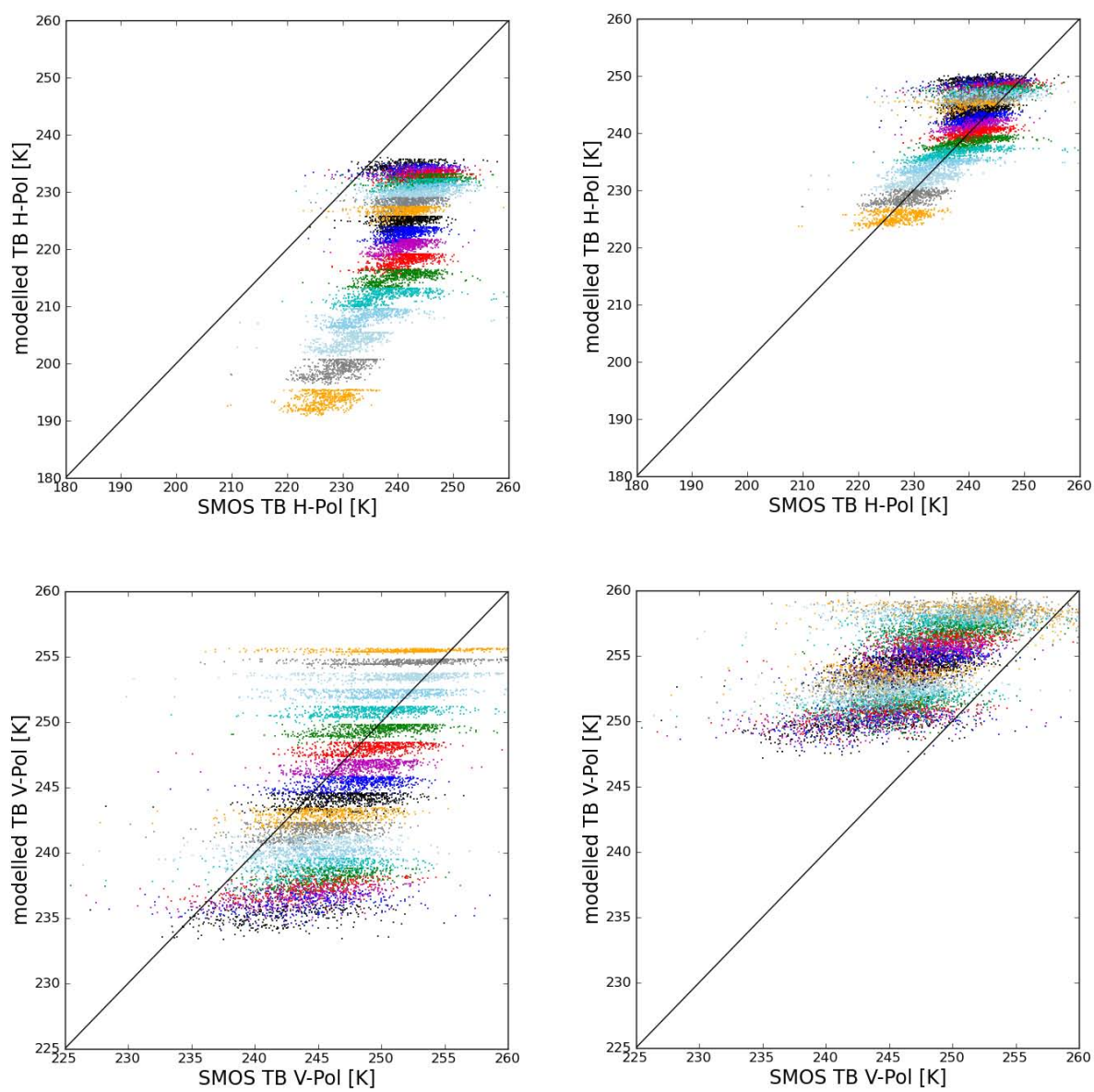

Fig. 5. Brightness temperatures as measured by SMOS vs. brightness temperatures as modelled with the model for one ice layer and the IceBridge ice thicknesses (left figures), and as modelled with the model for one ice and one snow layer and the IceBridge ice and snow thicknesses (right figures), respectively. The upper figures show horizontal polarisation, the lower figures vertical polarisation. The colors indicate the incidence angle increasing from 0 at the upper right corner to $60^{\circ}$ at the lower left corner of the data cloud at horizontal polarisation, and from 0 at the lower left corner to $60^{\circ}$ at the upper right corner at vertical polarisation. Only data points with $c_{\text {ice }} \geq 95 \%$ and $-37.3{ }^{\circ} \mathrm{C}<T_{\text {surf }}<-28.3^{\circ} \mathrm{C}$ are included.

Weeks, 1974). For the surface temperature, we use the average value of all $\mathrm{KT} 19$ values, i.e. $T_{\text {surf }}=-32.8^{\circ} \mathrm{C}$.

The mean brightness temperatures, averaged over the whole incidence angle range, observed for the average snow thicknesses of the five snow thickness classes are shown in Fig. 6. In general, the observed brightness temperatures increase with increasing snow thickness for both horizontal and vertical polarisation. The mean brightness temperature observations at horizontal polarisation increase by $1.5 \mathrm{~K}$ from snow thickness class 1 to 2 , by $2.3 \mathrm{~K}$ from snow thickness class 2 to 3 , by additional $0.9 \mathrm{~K}$ for snow thickness class 4 , and another $0.5 \mathrm{~K}$ for snow thickness class 5 . At vertical polarisation, observed mean brightness temperatures increase by $1.3 \mathrm{~K}$ from snow thickness class 1 to 2 , and by $2.1 \mathrm{~K}$ from 2 to 3 . For snow thickness classes 3 to 5 , that is, for snow thicknesses $d_{\text {snow }}=20-40 \mathrm{~cm}$, the vertically polarised brightness temperatures are very similar and differ by only $0.4 \mathrm{~K}$.
Brightness temperatures increase more pronouncedly from snow thickness class 2 to 3 , than from 1 to 2 . This reflects the fact, that the average snow thicknesses of snow thickness classes 1,2 , and 3 are $11.8 \mathrm{~cm}, 16.7 \mathrm{~cm}$, and $23.6 \mathrm{~cm}$, respectively. Thus, snow thickness from 1 to 2 increases on average by $4.9 \mathrm{~cm}$, while snow thickness from 2 to 3 increases on average by $6.9 \mathrm{~cm}$. For the other cases, the increase of brightness temperatures with increasing snow thickness is smaller for higher snow thicknesses. When we compare the observed brightness temperatures with the modelled brightness temperatures, the mean deviations at horizontal polarisation are 2.4 and $1.8 \mathrm{~K}$ for the snow thickness classes 1 and 2, respectively; the mean deviations for the snow thickness classes 3 to 5 are between 0.2 and $0.5 \mathrm{~K}$. The horizontally polarised brightness temperatures are thus on average slightly overestimated by the model, when compared to the observations. At vertical polarisation, we find that the model systematically overestimates the observed brightness temperatures by 


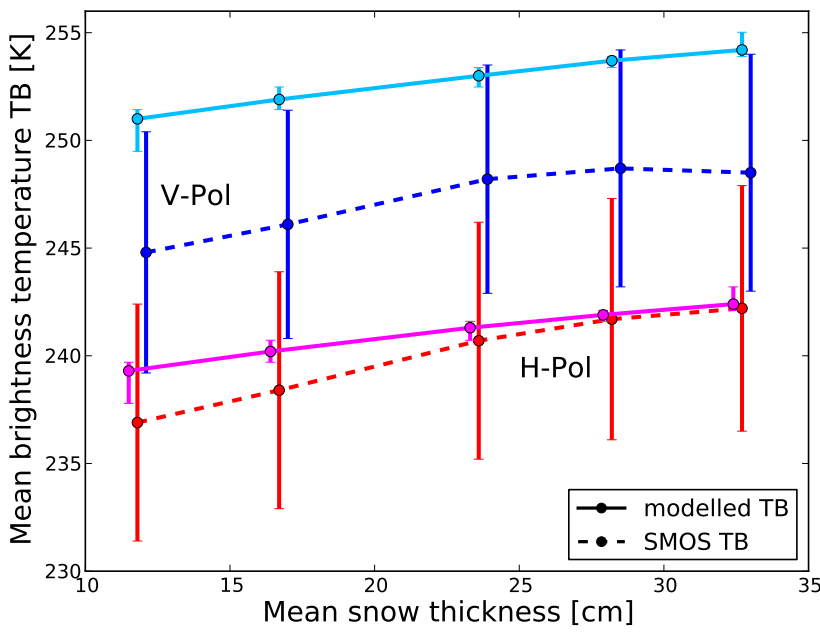

Fig. 6. Brightness temperatures averaged over the incidence angle range $0-60^{\circ}$ as simulated (solid line) and as observed by SMOS (dashed line) at horizontal (reddish colors) and at vertical (bluish colors) polarisation vs. the average snow thickness of the snow thickness classes 1-5. For the SMOS observations, the error bars indicate the average standard deviation of the different incidence angle ranges. For the simulations, the error bars indicate the modelled brightness temperature range for the range of snow thicknesses contained within each class.

4.8 to $6.2 \mathrm{~K}$ for the five snow thickness classes. When we try different values for the ice temperature, snow density, and ice salinity (not shown here), we find that only the ice salinity impacts the modelled brightness temperatures such that the deviations between the observations and the model are more evenly distributed for horizontal and for vertical polarisation, such that the horizontally polarised brightness temperatures are slightly underestimated and the vertically polarised brightness temperatures are slightly overestimated by the model. However, this is only the case for a very low ice salinity of $S_{\text {ice }}=1 \mathrm{~g} \mathrm{~kg}^{-1}$, because brightness temperatures are very sensitive to ice salinity for low ice salinities (Maaß, 2013). For ice salinities $S_{\text {ice }} \geq 1.5 \mathrm{~g} \mathrm{~kg}^{-1}$, the brightness temperatures are only slightly influenced by ice salinity. Because we can expect an ice salinity of $1 \mathrm{~g} \mathrm{~kg}^{-1}$ to be too low a value for the average ice salinity of the sea ice in the IceBridge campaign area, we expect the results shown here to be representative of our sea ice radiation model in its current state.

The angular dependencies of the observed and simulated brightness temperatures for the five snow thickness classes are shown in Fig. 7. For low incidence angles $\theta<20^{\circ}$, modelled brightness temperatures are about 5- $8 \mathrm{~K}$ higher than the observed brightness temperatures. This is in accordance with reports about problems with the SMOS brightness temperature processor that cause brightness temperatures for low incidence angles to be 3-5 K too low (M. Martin-Neira, personal communication, 2013).

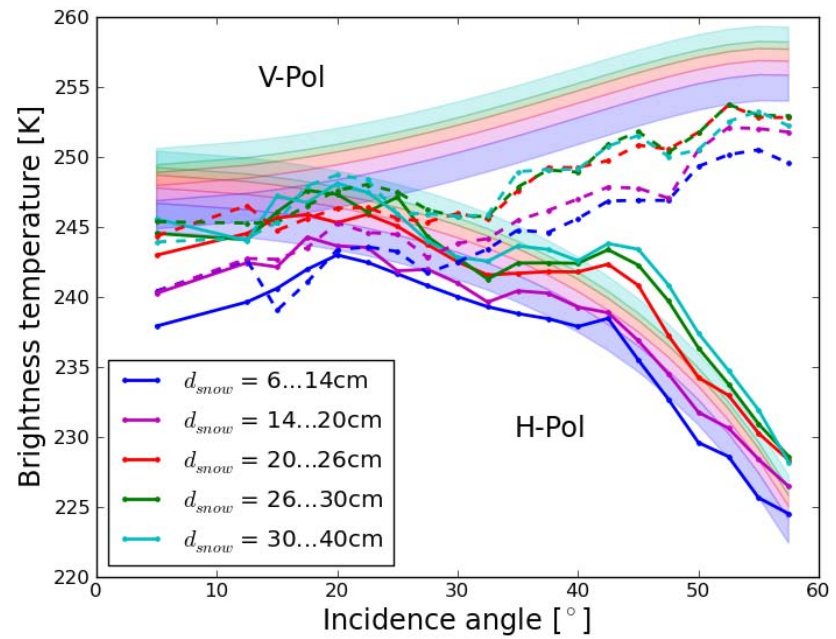

Fig. 7. Brightness temperatures as simulated and as measured by SMOS for the snow thickness classes $1-5$ as given in the figure legend. The shaded areas indicate the brightness temperature simulations, the lines indicate the averaged brightness temperature measurements. The solid lines indicate horizontal polarisation, the dashed lines indicate vertical polarisation.

\subsection{Comparison of retrieved and measured snow thicknesses}

The results from the previous sections suggest that brightness temperatures at vertical polarisation are less affected by the presence of a snow cover than the brightness temperatures at horizontal polarisation. The brightness temperature's sensitivity to snow thickness appears to be similar for horizontal and vertical polarisation. However, our radiation model reproduces the absolute values of the observed brightness temperatures of snow-covered thick sea ice considerably better for horizontal than for vertical polarisation. Thus, here we focus on investigating whether horizontally polarised brightness temperatures as observed by SMOS have the potential for the retrieval of snow thickness over thick Arctic sea ice. For comparison, we also consider the retrieval as obtained from vertically polarised brightness temperatures. In order to investigate how successfully we can retrieve snow thickness over thick sea ice from SMOS, we use different simulation scenarios to simulate brightness temperatures at horizontal and at vertical polarisation over a range of incidence angles. In these simulation scenarios, we use fixed values for all model input parameters and perform the simulations for different snow thicknesses $\left(d_{\text {snow }}=0-70 \mathrm{~cm}\right)$. These simulated brightness temperatures are then compared with observed SMOS brightness temperatures over a range of incidence angles. The retrieved snow thickness is the snow thickness that is related to the simulation that has the lowest root mean square deviation between the simulated and the observed brightness temperatures. 
Table 3. Minimum, maximum, and mean root mean square deviations RMSD and coefficients of determination $r^{2}$ for the IceBridge snow thicknesses and the snow thicknesses as retrieved from SMOS brightness temperatures for the 15 simulation scenarios. The values are given for the retrieval with horizontally and with vertically polarised brightness temperatures, as well as for horizontally polarised brightness temperatures, when only retrieved snow thicknesses $d_{\text {snow }}<35 \mathrm{~cm}$ are considered.

\begin{tabular}{llrrr}
\hline & & Min & Max & Mean \\
\hline \multirow{2}{*}{ RMSD [cm] } & H-Pol & 11.9 & 18.3 & 14.9 \\
& V-Pol & 12.5 & 24.0 & 20.2 \\
& H-Pol $\left(d_{\text {snow }}<35 \mathrm{~cm}\right)$ & 5.5 & 11.8 & 7.5 \\
\hline \multirow{2}{*}{$r^{2}$} & H-Pol & 0.43 & 0.58 & 0.54 \\
& V-Pol & 0.09 & 0.37 & 0.20 \\
& H-Pol $\left(d_{\text {snow }}<35 \mathrm{~cm}\right)$ & 0.49 & 0.63 & 0.58 \\
\hline
\end{tabular}

For the retrieval, we use the same pixels as in the above investigations but restrict the analysis to pixels that have measured ice concentration $c_{\text {ice }} \geq 95 \%$, and a surface temperature $-37.3^{\circ} \mathrm{C}<T_{\text {surf }}<-28.3^{\circ} \mathrm{C}$. Thus, we can assume an ice concentration $c_{\text {ice }}=100 \%$ and use a constant surface temperature. For the remaining model input parameters, we assume different values and perform 15 different scenarios. Thus, we pretend not to have exact information on the ice conditions when we retrieve snow thickness from SMOS data. In Sect. 4 , the ice surface temperature is assumed to be $T_{\text {surf }}=-32.8^{\circ} \mathrm{C}$, the bulk ice salinity is $S_{\text {ice }}=$ $1.5 \mathrm{~g} \mathrm{~kg}^{-1}$, the ice thickness is $d_{\text {ice }}=4 \mathrm{~m}$, and the snow density is $\rho_{\text {snow }}=320 \mathrm{~kg} \mathrm{~m}^{-3}$. For the retrieval we use different constant values within a range that we would consider to be realistic for the considered time and area, if we did not know the actual conditions during the flight campaign. For our simulations, we choose the surface temperature to take values between -39 and $-31{ }^{\circ} \mathrm{C}$, the bulk ice salinity is 1.5 or $2.5 \mathrm{~g} \mathrm{~kg}^{-1}$, the ice thickness is between 3 and $5 \mathrm{~m}$, and the snow density takes values between 280 and $340 \mathrm{~kg} \mathrm{~m}^{-3}$. Additionally, we consider simulations over the incidence angle range $15-50^{\circ}$ or $15-60^{\circ}$. The simulated brightness temperatures are then compared to SMOS brightness temperatures only using data from the day on which the corresponding IceBridge measurements took place, or additionally from the day before and after that day (i.e. we average the SMOS brightness temperatures over three days). The root mean square deviations and the coefficients of determination between the IceBridge snow thicknesses and the snow thicknesses retrieved from SMOS brightness temperatures for the 15 simulation scenarios are shown in Fig. 8. The corresponding minimum, maximum, and mean values for the root mean square deviations and the coefficients of determination are given in Table 3.

The results from the previous sections suggest that the sensitivity of brightness temperature to snow thickness de-

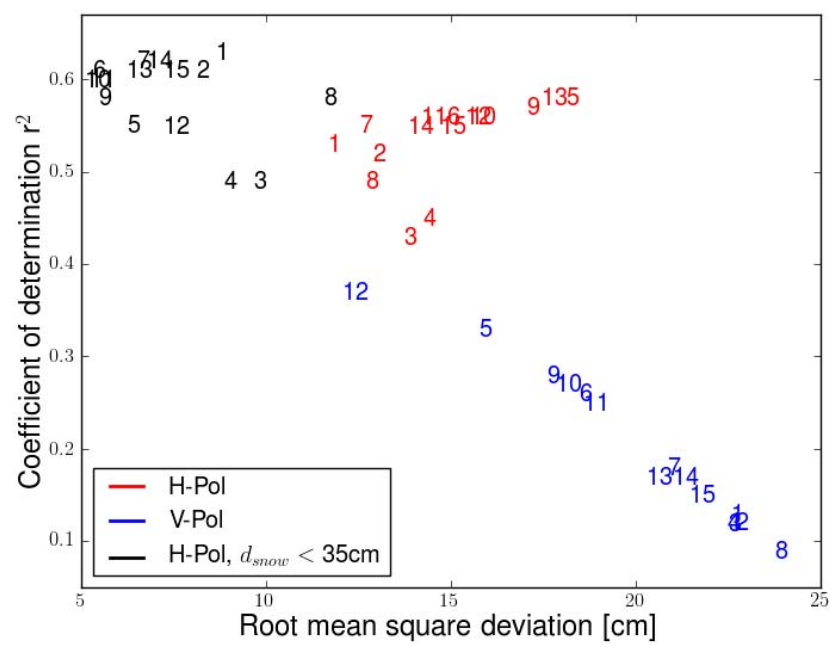

Fig. 8. Coefficients of determination $r^{2}$ and root mean square deviations for the IceBridge snow thicknesses and the snow thicknesses retrieved from SMOS brightness temperatures for 15 different simulation scenarios. The numbers give the scenario number. The red and blue numbers show the results for the consideration of all snow thicknesses. The red numbers indicate horizontal, the blue numbers vertical polarisation. The black numbers indicate the results for horizontal polarisation, when only snow thicknesses $d_{\text {snow }}<35 \mathrm{~cm}$ (as retrieved from SMOS) are considered.

creases with increasing snow thickness. Thus, the accuracy of a potential snow thickness retrieval from SMOS brightness temperatures is expected to be higher for lower snow thicknesses. Therefore, here we also compare only SMOS and IceBridge pixels for that the SMOS retrieval returns snow thicknesses $d_{\text {snow }}<35 \mathrm{~cm}$. For these lower snow thicknesses, only the results for horizontal polarisation are depicted in Fig. 8 and Table 3, because for vertical polarisation almost all retrieved snow thicknesses are below $35 \mathrm{~cm}$, even if they are not explicitly constrained to these values.

At vertical polarisation, the root mean square deviations and the coefficients of determination between the IceBridge and the SMOS snow thicknesses show an approximately linear relationship (Fig. 8). Lower coefficients of determination coincide with higher root mean square deviations, and higher coefficients of determination coincide with lower root mean square deviations. For the 15 simulation scenarios for vertical polarisation, the coefficients of determination $r^{2}$ take values between 0.09 and 0.37 , and the root mean square deviations between the IceBridge and the SMOS snow thicknesses range between 12.5 and $24.0 \mathrm{~cm}$. For the 15 simulation scenarios at horizontal polarisation, the coefficients of determination $r^{2}$ take values between 0.43 and 0.58 , on average we obtain a coefficient of determination $r^{2}=0.53$. The root mean square deviations between the IceBridge and the SMOS snow thicknesses range between 11.9 and $18.3 \mathrm{~cm}$, the average value being $14.9 \mathrm{~cm}$. 


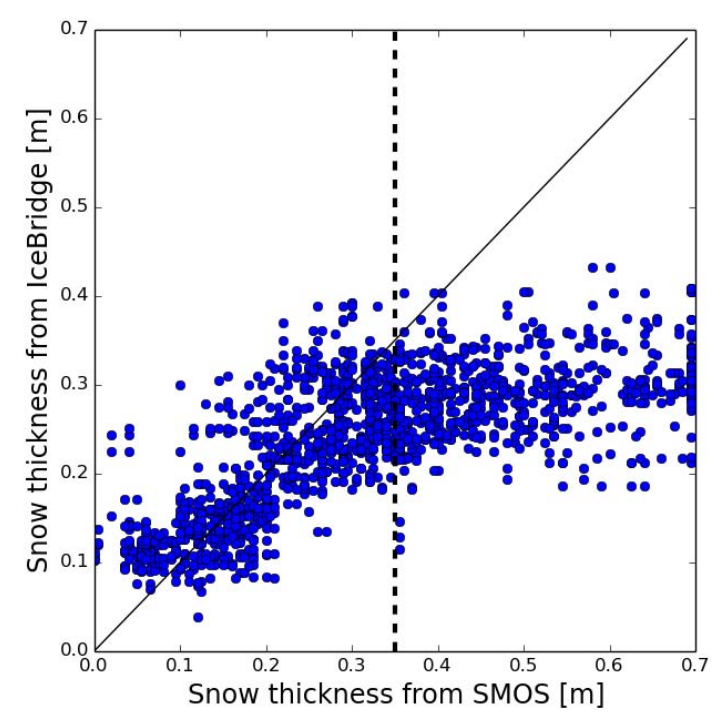

Fig. 9. Snow thicknesses as retrieved from horizontally polarised SMOS brightness temperatures vs. coincident snow thicknesses as measured during the IceBridge campaign. Here, we show the results for the simulation with $\theta=15-50^{\circ}, T_{\text {surf }}=-38.15^{\circ} \mathrm{C}, \rho_{\text {snow }}=$ $260 \mathrm{~kg} \mathrm{~m}^{-3}, d_{\text {ice }}=4 \mathrm{~m}$, and $S_{\text {ice }}=1.5 \mathrm{~g} \mathrm{~kg}^{-1}$ (simulation scenario no. 6). The dashed line indicates the result, if we consider only snow thicknesses for that the retrieval from SMOS brightness temperatures gives snow thicknesses $d_{\text {snow }}<35 \mathrm{~cm}$.

Thus, all coefficients of determination for horizontal polarisation are higher than for vertical polarisation, and most of the root mean square deviations are lower at horizontal polarisation. The ranges of values for both, the coefficients of determination and the root mean square deviations, are smaller at horizontal than at vertical polarisation. If we consider only pixels for that the retrieval from horizontally polarised SMOS brightness temperatures gives snow thicknesses $d_{\text {snow }}<35 \mathrm{~cm}$, the coefficients of determination increase, and the root mean square deviations are between 5.5 and $11.8 \mathrm{~cm}$, the average value being $7.5 \mathrm{~cm}$ (Table 3 ).

We choose the simulation scenario no. 6 to illustrate the comparison between IceBridge and SMOS snow thicknesses. This simulation scenario has the lowest root mean square deviation, when we consider only snow thicknesses retrieved to be $d_{\text {snow }}<35 \mathrm{~cm}$. In this simulation, the ice surface temperature is assumed to be $T_{\text {surf }}=-37^{\circ} \mathrm{C}$, the ice salinity is $S_{\text {ice }}=1.5 \mathrm{~g} \mathrm{~kg}^{-1}$, the ice thickness is $d_{\text {ice }}=4 \mathrm{~m}$, and the snow density is $\rho_{\text {snow }}=320 \mathrm{~kg} \mathrm{~m}^{-3}$. We consider simulations over the incidence angle range $15-50^{\circ}$, and we use SMOS brightness temperatures averaged over three days.

The comparison for all snow thicknesses shows a good average agreement for snow thicknesses up to about $30-35 \mathrm{~cm}$ and an overestimation of snow thicknesses, when the thickness retrieval returns higher values (Fig. 9). The minimum detectable snow thickness of the IceBridge snow radar is about $5 \mathrm{~cm}$ (Kwok et al., 2011), thus there are no values below $5 \mathrm{~cm}$ for the IceBridge snow thickness. The average Ice-

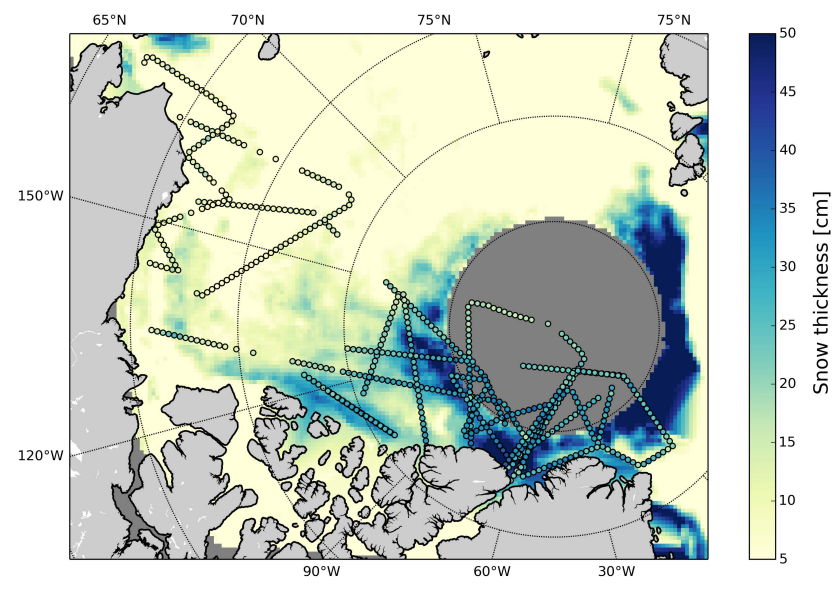

Fig. 10. Mean snow thickness field as retrieved from SMOS brightness temperatures averaged over 14-31 March 2012. The dots show IceBridge snow thicknesses, each averaged over $30 \mathrm{~km}$ of flight distance (if these contained at least 200 valid measurements).

Bridge snow thickness is $\overline{d_{\text {snow }}}=23.5 \mathrm{~cm}$, while the average snow thickness from the SMOS retrieval is $\overline{d_{\text {snow }}}=31.7 \mathrm{~cm}$. The coefficient of determination for the snow thicknesses of this simulation scenario is $r^{2}=0.56$, and the root mean square deviation is $15.1 \mathrm{~cm}$.

If we consider only snow thicknesses retrieved to be $d_{\text {snow }}<35 \mathrm{~cm}$, the coefficient of determination for the snow thicknesses of this simulation scenario is $r^{2}=0.61$, and the root mean square deviation is $5.5 \mathrm{~cm}$. The average IceBridge snow thickness is $\overline{d_{\text {snow }}}=19.9 \mathrm{~cm}$, and the average snow thickness from the SMOS retrieval is $\overline{d_{\text {snow }}}=20.0 \mathrm{~cm}$. Thus, the average snow thicknesses differ by only $0.1 \mathrm{~cm}$.

We use the parameter settings of the above described simulation to produce a first snow thickness map for the Arctic and to compare the spatial distributions of the snow thicknesses as measured during the IceBridge campaign and as obtained from the SMOS snow thickness retrieval from brightness temperatures averaged over 14 to 31 March 2012 (Fig. 10). In accordance with the IceBridge measurements, this first SMOS snow thickness map reveals a thinner snow cover in the Canadian Arctic (about 130 to $180^{\circ} \mathrm{W}$ longitude), and a thicker snow cover towards the coast of Greenland (about 0 to $120^{\circ} \mathrm{W}$ ).

\section{Summary and discussion}

In this study, we used an emission model developed by Burke et al. (1979) and empirical relationships for the ice and snow permittivities to calculate L-band brightness temperatures of snow-covered sea ice. When we assume values for the ice surface temperature and the ice salinity, the emission model describes the brightness temperature of a slab of ice above a semi-infinite layer of water as a function of the ice thickness. Additionally, a snow layer with a certain density (and 
wetness) on top of the ice layer can be included in the model. When we added a snow layer on top of the sea ice, we obtained a brightness temperature increase because of the lower reflectivities of radiation at the air-snow and the snow-ice boundaries as compared to the air-ice boundary. Thus, more of the radiation originating from within the ice is observable above a snow-covered ice layer than above a bare ice layer. The difference between the brightness temperatures of snow-covered sea ice and bare sea ice is larger at horizontal polarisation than at vertical polarisation. Because dry snow is almost transparent in L-band, only a very small fraction of the radiation from the underlying ice is attenuated on its way through the snow layer to the surface, and the thickness of the snow layer does not influence the dielectric properties of the snow layer. The brightness temperature above snow-covered sea ice depends only on the snow layer's thickness because the thickness of the snow layer influences the temperature of the underlying sea ice, which in turn influences the brightness temperature. Thus, there is an indirect dependence between snow thickness and brightness temperature.

In order to test the validity of our results from the theoretical investigations, we used snow and ice thickness measurements from the IceBridge flight campaign in spring 2012 in the Arctic to simulate brightness temperatures and to compare these simulated brightness temperatures with brightness temperatures measured by SMOS. In agreement with the findings from the model simulations in the previous section, we obtained two main findings. Firstly, the observed SMOS brightness temperatures were considerably underestimated when we neglected the snow layer in our model simulations. Secondly, the horizontally polarised brightness temperatures were more affected by the presence of a snow layer than the vertically polarised brightness temperatures.

The reasons for the deviations between the simulated and the observed brightness temperatures are mainly the remaining uncertainties for the ice and snow thicknesses, the ice concentration, the ice temperature, and the ice salinity. While we had information on the former ice parameters, the ice salinity was only roughly estimated from the ice thickness using an empirical relationship between ice salinity and thickness. The IceBridge measurements were mainly taken over thick sea ice. The average value was $4 \mathrm{~m}$ and there were only very few measurements over sea ice with a thickness lower than $1 \mathrm{~m}$. At these high ice thicknesses, ice thickness itself does not have a large impact on brightness temperature. However, the salinity of thick sea ice is usually low, and studies on the brightness temperature's sensitivity to ice salinity variations have shown a very high sensitivity for low ice salinities (Maaß, 2013). Hence, knowledge on ice salinity is more crucial for thick multi-year ice with low salinities, as considered here, than for thin first-year ice with high salinities. We were not able to figure out why our simulations and the observations agreed better at horizontal than at vertical polarisation. We may hypothesise that this is related to the roughness of the ice. However, because our current radiation model does not account for roughness effects, we cannot investigate this at the moment.

In accordance with our theoretical considerations, we found that observed SMOS brightness temperatures increased with increasing snow thickness. From the snow thickness class with $d_{\text {snow }}=6-14 \mathrm{~cm}$ to the snow thickness class with $d_{\text {snow }}=30-40 \mathrm{~cm}$, SMOS brightness temperatures, averaged over all incidence angles, increased by $5.3 \mathrm{~K}$ at horizontal polarisation, and by $3.7 \mathrm{~K}$ at vertical polarisation. The observed increases were somewhat higher than the modelled increases of $3.1 \mathrm{~K}$ at horizontal, and $3.2 \mathrm{~K}$ at vertical polarisation.

For the attempt to retrieve snow thickness from SMOS brightness temperatures, we set up different simulations that assumed different constant values for the model input parameters surface temperature, ice salinity, ice thickness, and snow density. There are mainly two reasons, why we used constant values for the ice thickness and the ice surface temperature in the parts where we retrieved snow thickness from SMOS data. Firstly, we assume that for a potential retrieval of snow thickness from SMOS data in the future, we would not have information on the ice thickness and the surface temperature, at least not for each pixel separately. Thus, we here tried to find out how well the retrieval may succeed when we cannot prescribe ice thickness and temperature accurately in the retrieval model. Secondly, when we compare Fig. 4 with Fig. 5, we see that the variable ice surface temperature (in addition to the variable ice concentration) has a quite large impact on the variability of the simulated brightness temperatures, not necessarily matching the variability of the SMOS observations. Several reasons are conceivable for the lower agreement when accounting for the variability of surface temperature: (1) the temporal and/or spatial offset between the IceBridge and the SMOS data, the first one representing values measured within minutes, the latter one having been averaged over three days; (2) an incompletely incorporated relationship between the surface temperature, its variability and the bulk ice temperature in the model; or (3) uncertainties in the IceBridge temperature measurements, for example.

For the retrieval model's input parameters, we assumed values within ranges that are likely to occur in nature. Thus, we were able to estimate how the retrieval would perform under the least suitable and under the most suitable assumptions for the above mentioned ice parameters, if we had no exact information on ice conditions. Ideally, we would have performed the simulations for all possible combinations of the ice parameters that were varied here. However, we think that the 15 selected scenarios representatively cover the range of conceivable settings and the corresponding results. Here, the surface temperatures were varied only over a range of $8^{\circ} \mathrm{C}$, because we can assume that for the retrieval of snow thickness from SMOS brightness temperatures, we would have at least some information on ice temperature, for example from 
air temperatures, which are available from observations or near-real-time reanalysis data.

Here, we used a retrieval method based on discretized snow thickness values. More continuous results would have been obtained, if we had used a gradient method, for which the deviation between simulated and observed brightness temperatures quickly approaches towards minimum values. Thus, we would not have to compare simulated and observed brightness temperatures for the entire snow thickness range and could resolve snow thicknesses on a finer scale. However, as the accuracy of the snow thickness retrieval is in the order of several centimetres, the results from a retrieval approach giving finer resolved snow thicknesses would not differ from our findings here. Though, such a gradient based retrieval approach could be more advisable for large-scale retrieval of snow thickness.

A conceivable reason for the observed dependence between snow thickness and brightness temperature is that brightness temperature actually depends on ice thickness (even if the ice is very thick). If this was the case, we would possibly observe a dependence between snow thickness and brightness temperature, because snow thickness is related to ice thickness, as, for example, assumed in the calculations of Doronin (1971), who estimated that snow thickness is on average $10 \%$ of ice thickness (for ice thicknesses $d_{\text {ice }}>20 \mathrm{~cm}$ ). In order to exclude this possibility, we tried to retrieve ice thickness with the same approach as for the snow thickness (not shown here). The correlation between retrieved and observed ice thicknesses was negative with $r^{2} \approx 0.2$, and root mean square deviations were almost $4 \mathrm{~m}$, confirming that the observed brightness temperatures cannot be mainly attributed to ice thickness.

Here, the retrieval exploited the SMOS measurement principle of observing brightness temperatures not only under one incidence angle but for a range of incidence angles. With the current sea ice radiation model the retrieval was not successful, when we considered only single SMOS measurements or SMOS brightness temperatures from certain incidence angles. One reason is that the SMOS brightness temperatures have a relatively high variability. Thus, we need to average over as many measurements as possible in order to extract any information from the brightness temperatures. A second reason is, that with our radiation model we succeeded to simulate brightness temperatures averaged over a range of incidence angles such that they agreed well with SMOS measurements. However, the SMOS brightness temperatures showed some oscillations, when considered as a function of incidence angle. Using our model, at the present state, we were not able to reproduce these oscillations with increasing incidence angle, but only the average brightness temperature over the incidence angle range. These observed oscillations could be related to roughness effects on the ice and snow surface, which are not taken into account by our model.

Our snow thickness map obtained from SMOS measurements showed a good spatial agreement with the IceBridge snow thicknesses. The areas outside the IceBridge campaign area should be interpreted more carefully, because we used constant values for the model input parameters ice temperature, ice salinity, and snow density, as we estimated them from the conditions found during the IceBridge flight campaign. The highest deviations between SMOS and IceBridge snow thicknesses were found east of Greenland around the longitude of $0^{\circ}$. In this area, surface air temperature data show highly variable temperatures with very warm conditions. Thus, the snow could partly be wet, contradicting our assumption of dry snow. Besides when we assume too low temperatures in the retrieval, we obtain an overestimation of snow thickness. Additionally, due to the high variability of temperatures our approach of assuming constant values for the ice temperature may lead to higher uncertainties in the snow thickness retrieval than in areas with more constant temperature conditions. Furthermore, the SSMIS ice concentration data in this area show a considerably higher variability than in the remaining areas. Our approach of excluding SMOS measurements over low ice concentration areas is based on 5 day median filtered SSMIS data. Over the highly variable ice concentration field, this approach may fail and the considered SMOS pixels may contain water areas. In this case, we would observe considerably lower brightness temperatures and would underestimate snow thickness. A future improved snow thickness retrieval from SMOS brightness temperatures should thus include temperature information and more carefully take into account ice concentration variability.

Finally, we try to assess the applicability of our SMOS snow thickness retrieval to Antarctic sea ice. On the one hand, the generally higher ice salinity of Antarctic sea ice causes the brightness temperature to saturate more rapidly with regard to the brightness temperature's sensitivity to ice thickness. This results in a broader range of ice thicknesses to be suitable for the snow thickness retrieval from L-band brightness temperatures. On the other hand, several conditions would make the retrieval more difficult than for Arctic sea ice: the more divergent ice cover in the Antarctic causes ice concentrations to be more variable, which introduces large uncertainties to the retrieval. Furthermore, the often wet snow cover and the less distinct transition between ice and snow at the ice-snow interface are likely to be unfavourable for the retrieval of snow thickness from SMOS data in the Antarctic.

\section{Conclusions}

According to our emission model, snow has a twofold impact on sea ice brightness temperatures. Firstly, the presence of a snow layer modifies the radiation observed above sea ice, because the reflectivities between the air-snow and the snow-ice boundaries are lower than the reflectivity at the air-ice boundary. Secondly, the thermal insulation by snow 
modifies the ice temperature and thus the ice permittivity. The first effect causes brightness temperatures above snowcovered sea ice to be higher than above snow-free sea ice. At horizontal polarisation, this increase of brightness temperature increases with increasing incidence angle $\theta$ and reaches almost $20 \mathrm{~K}$ at $\theta=45^{\circ}$ (for $d_{\text {ice }}=50 \mathrm{~cm}$ ). In contrast, at vertical polarisation, the brightness temperature increase due to the presence of a snow cover decreases with increasing incidence angle. At $\theta=45^{\circ}$, vertically polarised brightness temperatures of snow-covered and snow-free sea ice are almost identical, if the second effect, the thermal insulation by snow, is neglected. The presence of a snow layer appears as a sudden increase of brightness temperature in our emission model, because the model fails to describe the transition from no snow to a very thin snow cover (of a few $\mathrm{cm}$ ). Apart from this sudden increase, brightness temperatures in our emission model are nearly independent of the thickness of the snow layer, because snow is almost transparent in Lband. However, this holds only if we neglect the thermal insulation effect by snow. The influence of the snow's thermal insulation on sea ice brightness temperatures depends on the surface temperature conditions. For the relatively cold conditions considered here (ice surface temperature below $-10^{\circ} \mathrm{C}$ ), thermal insulation causes brightness temperatures to increase with increasing snow thickness.

Comparisons between simulated and observed brightness temperatures for snow-covered thick ice in the Arctic confirmed that horizontal polarisation is more affected by the presence of a snow layer than vertical polarisation. At horizontal polarisation, the root mean square deviation between simulated and observed brightness temperatures, averaged over the SMOS incidence angle range $\left(\theta=0-60^{\circ}\right)$, reduced by more than $15 \mathrm{~K}$, when a snow layer was taken into account. We found that for the model simulations with snow, modelled brightness temperatures agreed well with observations at horizontal polarisation, while the model overestimated the observations by about $3-7 \mathrm{~K}$ at vertical polarisation. In agreement with our model results, SMOS brightness temperatures observed over snow-covered thick Arctic sea ice increased with increasing snow thickness, when averaged over about 100-150 SMOS grid cells.

Due to the better agreement between simulations and observations at horizontal than at vertical polarisation, we used SMOS brightness temperatures at horizontal polarisation to estimate snow thickness over thick Arctic sea ice. The performance of the snow thickness retrieval depended on the model assumptions for ice temperature, ice salinity, ice thickness, and snow density. For different model assumptions, the root mean square deviations between SMOS retrieved snow thicknesses and snow thicknesses measured during the IceBridge campaign ranged between 11.9 and $18.3 \mathrm{~cm}$, and the average root mean square deviation was $14.9 \mathrm{~cm}$. The coefficients of determination $r^{2}$ ranged between 0.43 and 0.58 . When we constrained the comparison to snow thicknesses retrieved to be lower than $35 \mathrm{~cm}$, the root mean square deviations ranged between 5.5 and $11.8 \mathrm{~cm}$, and the average root mean square deviation was $7.5 \mathrm{~cm}$. For the model assumptions with the lowest deviation from the observations, mean SMOS and IceBridge snow thicknesses were then around $20 \mathrm{~cm}$ and differed by only $0.1 \mathrm{~cm}$. A first SMOS snow thickness map showed a realistic distribution of snow thicknesses for the Arctic. For an operational snow thickness retrieval, the input values for surface temperature, ice salinity, ice thickness and snow density would not be constant values (as assumed here), but would account for spatial and temporal variations and could be based on climatological estimations, reanalysis data or additional satellite observations. We consider this as future work.

To conclude, the thickness of the snow layer on sea ice has an indirect effect on L-band brightness temperatures, because ice that is covered by a thicker snow layer is warmer than ice covered by a thinner snow layer. Under relatively cold conditions (here: $-30^{\circ} \mathrm{C}$ surface temperature) this allows us to reasonably estimate snow thickness from horizontally polarised SMOS brightness temperatures over thick sea ice, here considered as ice thicker than about $1-1.5 \mathrm{~m}$.

Acknowledgements. The authors would like to thank the members of the ESA SMOSIce project for helpful discussions, and two anonymous reviewers for their constructive comments. This work was largely supported by the International Max Planck Research School on Earth System Modelling, and in parts through the Cluster of Excellence "CliSAP" (EXC177), University of Hamburg, funded through the German Science Foundation (DFG). SMOS data were provided by the ESA Support to Science Element programme under contract 4000101476. Ice concentration data retrieved from SSMIS measurements were provided by the Integrated Climate Data Center (ICDC), CliSAP/KlimaCampus, University of Hamburg, http://icdc.zmaw.de. IceBridge ice and snow thicknesses, and surface temperatures were provided by the NASA Distributed Active Archive Center at the National Snow and Ice Data Center, Boulder, Colorado USA. Digital media. http://nsidc.org/data/idcsi2.html.

Edited by: J. Stroeve

\section{References}

Alexandrov, V., Sandven, S., Wahlin, J., and Johannessen, O. M.: The relation between sea ice thickness and freeboard in the Arctic, The Cryosphere, 4, 373-380, doi:10.5194/tc-4-373-2010, 2010.

Andersen, S., Tonboe, R., Kaleschke, L., Heygster, G., and Pedersen, L.: Intercomparison of passive microwave sea ice concentration retrievals over the high-concentration Arctic sea ice, J. Geophys. Res, 112, C08004, doi:10.1029/2006JC003543, 2007.

Bourke, R. and Garrett, R.: Sea ice thickness distribution in the Arctic Ocean, Cold Reg. Sci. Technol., 13, 259-280, 1987.

Burke, W., Schmugge, T., and Paris, J.: Comparison of 2.8 and $21 \mathrm{~cm}$ microwave radiometer observations over soils with emission model calculations, J. Geophys. Res., 84, 287-294, 1979. 
Camps, A., Gourrion, J., Tarongi, J., Gutierrez, A., Barbosa, J., and Castro, R.: RFI analysis in SMOS imagery, in: Proceedings IGARSS, 2007-2010, 2010.

Comiso, J., Cavalieri, D., and Markus, T.: Sea ice concentration, ice temperature, and snow depth using AMSR-E data, IEEE T. Geosci. Remote, 41, 243-252, 2003.

Cox, G. and Weeks, W.: Salinity variations in sea ice, J. Glaciol., 13, 109-120, 1974.

Cox, G. and Weeks, W.: Equations for determining the gas and brine volumes in sea ice samples, J. Glaciol., 29, 306-316, 1983.

Doronin, Y.: Thermal interaction of the atmosphere and the hydrosphere in the Arctic, CoronetBooks, Philadelphia, 1971.

Eicken, H.: Salinity profiles of Antarctic sea ice: Field data and model results, J. Geophys. Res., 97, 15545-15557, 1992.

Farrell, S., Kurtz, N., Connor, L., Elder, B., Leuschen, C., Markus, T., McAdoo, D., Panzer, B., Richter-Menge, J., and Sonntag, J.: A first assessment of IceBridge snow and ice thickness data over Arctic sea ice, IEEE T. Geosci. Remote, 50, 20982111, 2012.

Giles, K., Laxon, S., Wingham, D., Wallis, D., Krabill, W., Leuschen, C., McAdoo, D., Manizade, S., and Raney, R.: Combined airborne laser and radar altimeter measurements over the Fram Strait in May 2002, Remote Sens. Environ., 111, 182-194, 2007.

Hall, D.: Remote sensing applications to hydrology: imaging radar, Hydrolog. Sci. J., 41, 609-624, 1996.

Hall, D., Key, J., Casey, K., Riggs, G., and Cavalieri, D.: Sea ice surface temperature product from MODIS, IEEE T. Geosci. Remote, 42, 1076-1087, 2004.

Hallikainen, M.: Microwave radiometry of snow, Adv. Space Res., 9, 267-275, 1989.

Kaleschke, L., Lüpkes, C., Vihma, T., Haarpaintner, J., Bochert, A., Hartmann, J., and Heygster, G.: SSM/I sea ice remote sensing for mesoscale ocean-atmosphere interaction analysis, Can. J. Remote Sens., 27, 526-537, 2001.

Kaleschke, L., Maaß, N., Haas, C., Hendricks, S., Heygster, G., and Tonboe, R. T.: A sea-ice thickness retrieval model for $1.4 \mathrm{GHz}$ radiometry and application to airborne measurements over low salinity sea-ice, The Cryosphere, 4, 583-592, doi:10.5194/tc-4583-2010, 2010.

Kaleschke, L., Tian-Kunze, X., Maaß, N., Mäkynen, M., and Drusch, M.: Sea ice thickness retrieval from SMOS brightness temperatures during the Arctic freeze-up period, Geophys. Res. Lett., 39, L05501, doi:10.1029/2012GL050916, 2012.

Kerr, Y., Waldteufel, P., Wigneron, J., Martinuzzi, J., Font, J., and Berger, M.: Soil moisture retrieval from space: the Soil Moisture and Ocean Salinity (SMOS) mission, IEEE T. Geosci. Remote, 39, 1729-1735, 2001.

Klein, L. and Swift, C.: An improved model for the dielectric constant of sea water at microwave frequencies, IEEE T. Antenn. Propag., 25, 104-111, 1977.

Krabill, W. B.: IceBridge KT19 IR Surface Temperature, online, NASA DAAC at NSIDC, Boulder, Colorado, USA, 2012.

Kurtz, N.: IceBridge Quick Look Sea Ice Freeboard, Snow Depth, and Thickness Product Manual, 2012.

Kurtz, N. and Farrell, S.: Large-scale surveys of snow depth on Arctic sea ice from operation IceBridge, Geophys. Res. Lett., 38, L20505, doi:10.1029/2011GL049216, 2011.
Kurtz, N., Studinger, M., Harbeck, J., Onana, V., and Farrell, S.: IceBridge Sea Ice Freeboard, Snow Depth, and Thickness, online, NASA DAAC at NSIDC, Boulder, Colorado USA, 2012.

Kurtz, N., Farrell, S., Studinger, M., Galin, N., Harbeck, J., Lindsay, R., Onana, V., Panzer, B., and Sonntag, J.: Sea ice thickness, freeboard, and snow depth products from Operation IceBridge airborne data, The Cryosphere, 7, 1035-1056, doi:10.5194/tc-71035-2013, 2013.

Kwok, R. and Cunningham, G.: ICESat over Arctic sea ice: estimation of snow depth and ice thickness, J. Geophys. Res., 113, C08010, doi:10.1029/2008JC004753, 2008.

Kwok, R., Panzer, B., Leuschen, C., Pang, S., Markus, T., Holt, B., and Gogineni, S.: Airborne surveys of snow depth over Arctic sea ice, J. Geophys. Res., 116, C11018, doi:10.1029/2011JC007371, 2011.

Maaß, N.: Remote sensing of sea ice thickness using SMOS data, Reports on Earth System Science, 131, available at: www.mpimet.mpg.de/fileadmin/publikationen/Reports/WEB_ BzE_131.pdf, 2013.

Markus, T. and Cavalieri, D. J.: Snow depth distribution over sea ice in the Southern Ocean from satellite passive microwave data, Antarct. Res. Ser., 74, 19-39, 1998.

Massom, R., Drinkwater, M., and Haas, C.: Winter snow cover on sea ice in the Weddell Sea, J. Geophys. Res., 102, 1101-1117, 1997.

Maykut, G. and Untersteiner, N.: Some results from a timedependent thermodynamic model of sea ice, J. Geophys. Res., 76, 1550-1575, 1971.

Menashi, J., Germain, K., Swift, C., Comiso, J., and Lohanick, A.: Low-frequency passive-microwave observations of sea ice in the Weddell Sea, J. Geophys. Res., 98, 22569-22577, 1993.

Misra, S. and Ruf, C.: Analysis of radio frequency interference detection algorithms in the angular domain for SMOS, IEEE T. Geosci. Remote, 50, 1448-1457, 2012.

Oliva, R., Daganzo, E., Kerr, Y., Mecklenburg, S., Nieto, S., Richaume, P., and Gruhier, C.: SMOS radio frequency interference scenario: status and actions taken to improve the RFI environment in the 1400-1427-MHz passive band, IEEE T. Geosci. Remote, 50, 1427-1439, 2012.

Pinori, S., Crapolicchio, R., and Mecklenburg, S.: Preparing the ESA-SMOS (soil moisture and ocean salinity) mission-overview of the user data products and data distribution strategy, in: Microwave Radiometry and Remote Sensing of the Environment, MICRORAD, IEEE, 1-4, 2008.

Pounder, E.: The Physics of Ice, Pergamon Press, the Commonwealth and International Library, Geophysics Division, Oxford, 1965.

Rothrock, D., Yu, Y., and Maykut, G.: Thinning of the Arctic sea-ice cover, Geophys. Res. Lett., 26, 3469-3472, 1999.

Rott, H. and Mätzler, C.: Possibilities and limits of synthetic aperture radar for snow and glacier surveying, Ann. Glaciol., 9, 195199, 1987.

Spreen, G., Kaleschke, L., and Heygster, G.: Sea ice remote sensing using AMSR-E $89 \mathrm{GHz}$ channels, J. Geophys. Res., 113, C02S03, doi:10.1029/2005JC003384, 2008.

Stroeve, J. C., Markus, T., Maslanik, J. A., Cavalieri, D. J., Gasiewski, A. J., Heinrichs, J. F., Holmgren, J., Perovich, D. K., and Sturm, M.: Impact of surface roughness on AMSR-E sea ice products, IEEE T. Geosci. Remote, 44, 3103-3117, 2006. 
Tiuri, M., Sihvola, A., Nyfors, E., and Hallikainen, M.: The complex dielectric constant of snow at microwave frequencies, IEEE J. Oceanic Eng., 9, 377-382, 1984.

Tonboe, R.: Simulations of the snow covered sea ice surface temperature and microwave effective temperature at L-Band, in: ESA Support To Science Element (STSE) Final Report, edited by: Kaleschke, L., ESA ESTEC Contract No.: 4000101476/10/NL/CT, 380 pp., Univ. Hamburg, Institute of Oceanography, available at: https://icdc.zmaw.de/fileadmin/user_upload/icdc_Dokumente/ SMOSICE_FinalReport_2013.pdf, 2013.

Ulaby, F., Moore, R., and Fung, A.: Microwave Remote Sensing: Active and Passive, vol. 1 - Microwave Remote Sensing Fundamentals and Radiometry, Addison-Wesley, London, UK, 1981.

Untersteiner, N.: Calculations of temperature regime and heat budget of sea ice in the Central Arctic, J. Geophys. Res., 69, 4755$4766,1964$.
Vant, M., Ramseier, R., and Makios, V.: The complex-dielectric constant of sea ice at frequencies in the range $0.1-40 \mathrm{GHz}, \mathrm{J}$. Appl. Phys., 49, 1264-1280, 1978.

Warren, S., Rigor, I., Untersteiner, N., Radionov, V., Bryazgin, N., Aleksandrov, Y., and Colony, R.: Snow depth on Arctic sea ice, J. Climate, 12, 1814-1829, 1999.

Yu, Y. and Rothrock, D.: Thin ice thickness from satellite thermal imagery, J. Geophys. Res., 101, 25753-25766, 1996.

Zine, S., Boutin, J., Font, J., Reul, N., Waldteufel, P., Gabarró, C., Tenerelli, J., Petitcolin, F., Vergely, J., Talone, M., and Delwart, S.: Overview of the SMOS sea surface salinity prototype processor, IEEE T. Geosci. Remote, 46, 621-645, 2008. 